\title{
Chilenopeptins A and B, Peptaibols from the Chilean \\ Sepedonium aff. chalcipori KSH 883
}

Alexander Otto, ${ }^{\dagger}$ Annegret Laub,,$^{\dagger}$ Lucile Wendt,${ }^{\ddagger}$ Andrea Porzel, ${ }^{\dagger}$ Jürgen Schmidt,${ }^{\dagger}$ Götz Palfner,${ }^{\S}$

José Becerra, ${ }^{\S}$ Dirk Krüger,${ }^{\perp}$ Marc Stadler,${ }^{\star}$ Ludger Wessjohann, ${ }^{\dagger}, \|$ Bernhard Westermann, $,{ }^{\dagger},\|\|$ and Norbert Arnold ${ }^{*, \dagger}$

${ }^{\dagger}$ Department of Bioorganic Chemistry, Leibniz Institute of Plant Biochemistry, Weinberg 3, D-06120 Halle (Saale), Germany

‡ Department of Microbial Drugs, Helmholtz Centre for Infection Research, Inhoffenstrasse 7, D-38124 Braunschweig, Germany

${ }^{\S}$ Departamento de Botanica, Facultad de Ciencias Naturales y Oceanograficas, Universidad de Concepción, Casilla 160-C, Concepción, Chile

${ }^{\perp}$ Department of Soil Ecology, Helmholtz Centre for Environmental Research, Theodor-Lieser-Strasse 4, D-06120 Halle (Saale), Germany

॥ Institute of Chemistry, Faculty of Natural Sciences II, Martin Luther University Halle-Wittenberg, Kurt-Mothes-Strasse 2, D-06120 Halle (Saale), Germany

\section{- Supporting Information -}




\section{Table of contents}

- Initial morphological analysis of Sepedonium aff. chalcipori KSH 883...........Fig. S1

- Spectral data of natural chilenopeptins A and B

Figs. S2-S13

- Spectral data of synthetic chilenopeptins A and B .Figs. S14-S17

- Spectroscopic comparison of natural and synthetic chilenopeptins

Figs. S18-S24

- Spectral data of natural tylopeptins A and B

Figs. S25-S28

- Protocol of solid-phase peptide synthesis. Table S1

- HRESIMS $^{\mathrm{n}}$ data Tables S2-S3

- Phylogenetic data. Tables S4-S6 
Fig. S1. Initial morphological analysis of Sepedonium aff. chalcipori KSH 883. (A) Two week old culture grown on malt peptone agar; (B) hyaline phialoconidia (200x); (C) yellow, globose aleurioconidia (200x); (D) scanning electron micrograph of an aleurioconidium (5000x)

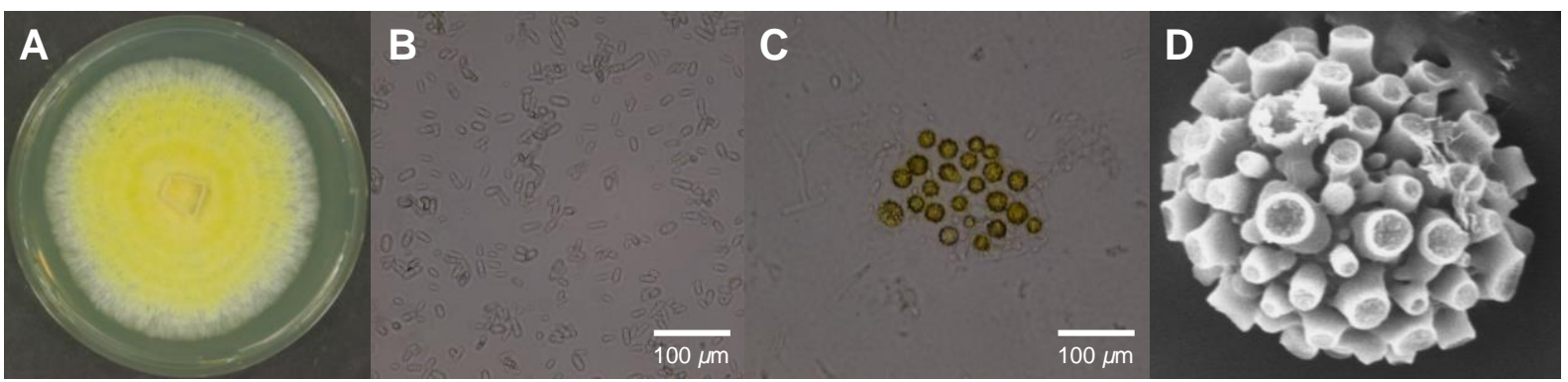

${ }^{a}$ Procedure for scanning electron microscopy of aleurioconidia: A thin layer of aleurioconidia originating from a 2-3 week old culture was fixed on metal stubs. After drying overnight at room temperature, samples were coated with a $1.4 \mathrm{~nm}$ gold-palladium layer in a Polaron SEM SC 515 Sputter Coater. Microscopy and photography were performed on a Digital Scanning Electron Microscop DSM 950 (Zeiss, Germany). 
Fig. S2. ${ }^{1} \mathrm{H}$ NMR spectrum of natural chilenopeptin A (1) $\left(600 \mathrm{MHz}, \mathrm{DMSO}-d 6,40{ }^{\circ} \mathrm{C}\right)$

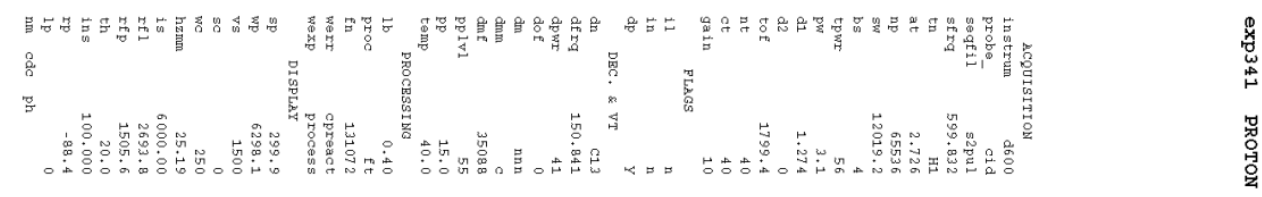

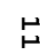




Fig. S3. ${ }^{13} \mathrm{C}$ NMR and DEPT-135 spectrum of natural chilenopeptin A (1) (150 MHz, DMSO-d6, 40 ${ }^{\circ} \mathrm{C}$ )




Fig. S4. ${ }^{1} \mathrm{H},{ }^{13} \mathrm{C}$ HSQC spectrum of natural chilenopeptin A (1) $\left(600 \mathrm{MHz}\right.$, DMSO-d6, $\left.40{ }^{\circ} \mathrm{C}\right)$

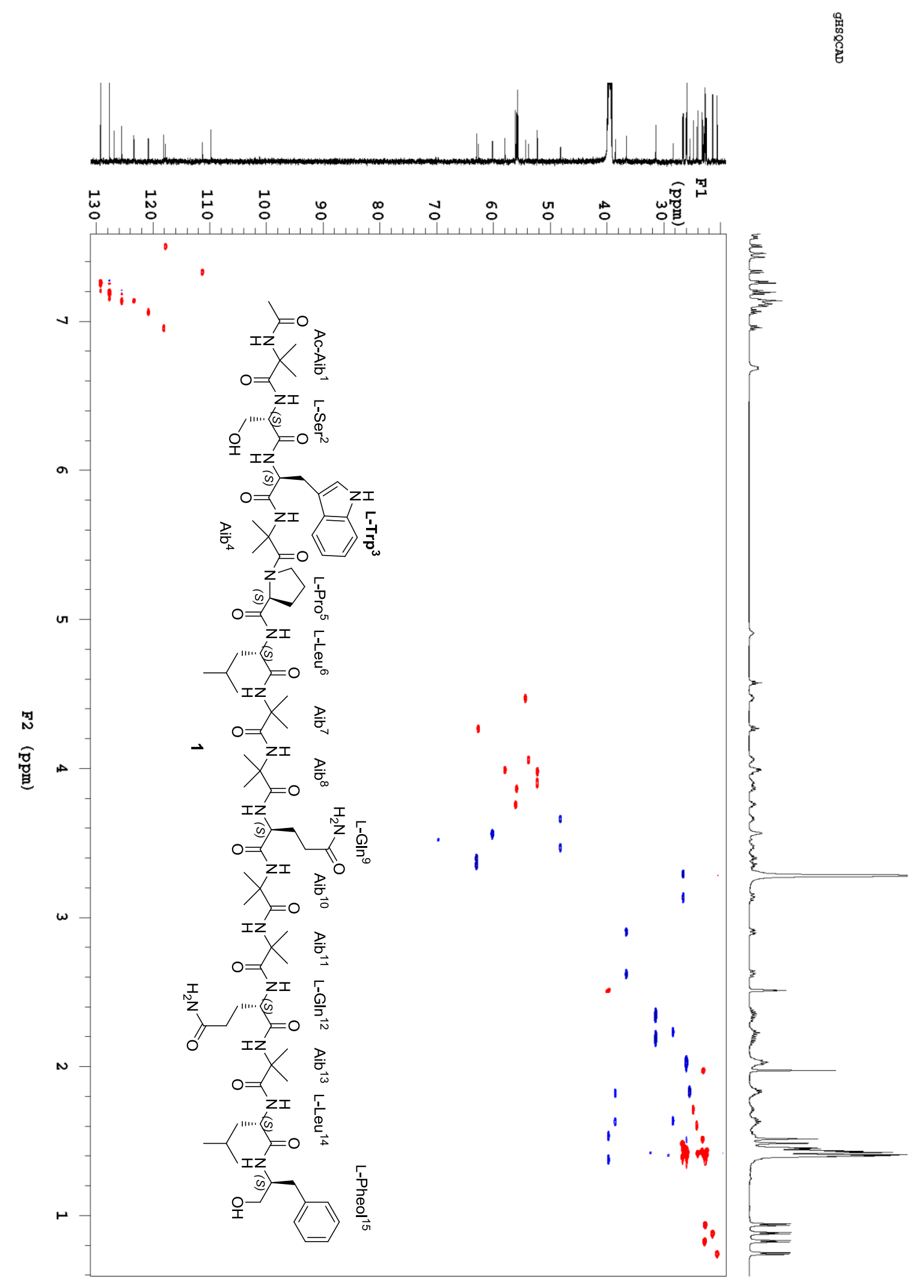


Fig. S5. ${ }^{1} \mathrm{H},{ }^{13} \mathrm{C}$ HMBC spectrum of natural chilenopeptin A (1) $\left(600 \mathrm{MHz}, \mathrm{DMSO}-d 6,40{ }^{\circ} \mathrm{C}\right)$

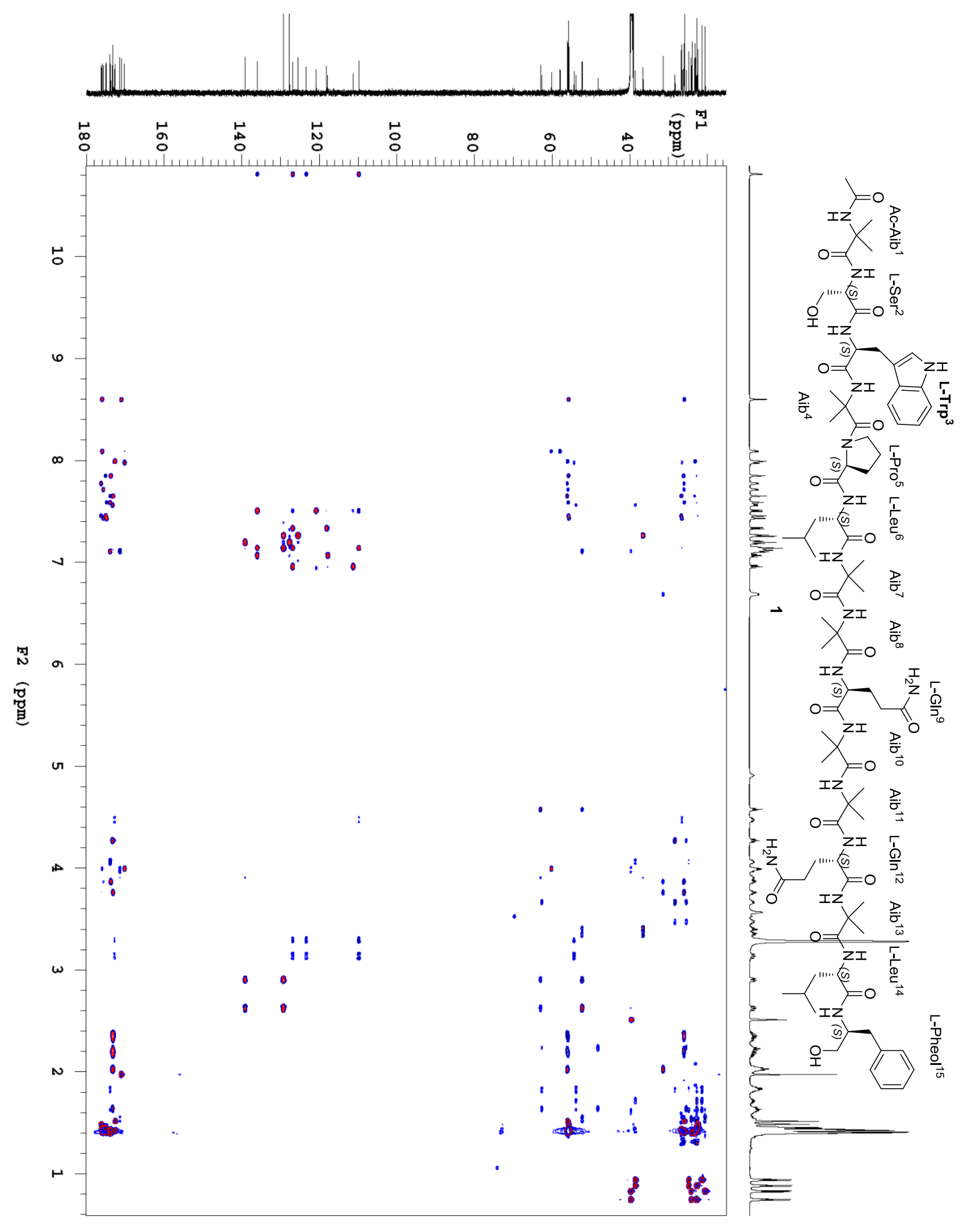


Fig. S6. ${ }^{1} \mathrm{H},{ }^{1} \mathrm{H}$ COSY spectrum of natural chilenopeptin A (1) $\left(600 \mathrm{MHz}, \mathrm{DMSO}-d 6,40{ }^{\circ} \mathrm{C}\right)$




Fig. S7. ${ }^{1} \mathrm{H},{ }^{1} \mathrm{H}$ ROESY spectrum of natural chilenopeptin A (1) $\left(600 \mathrm{MHz}, \mathrm{DMSO}-d 6,40{ }^{\circ} \mathrm{C}\right)$

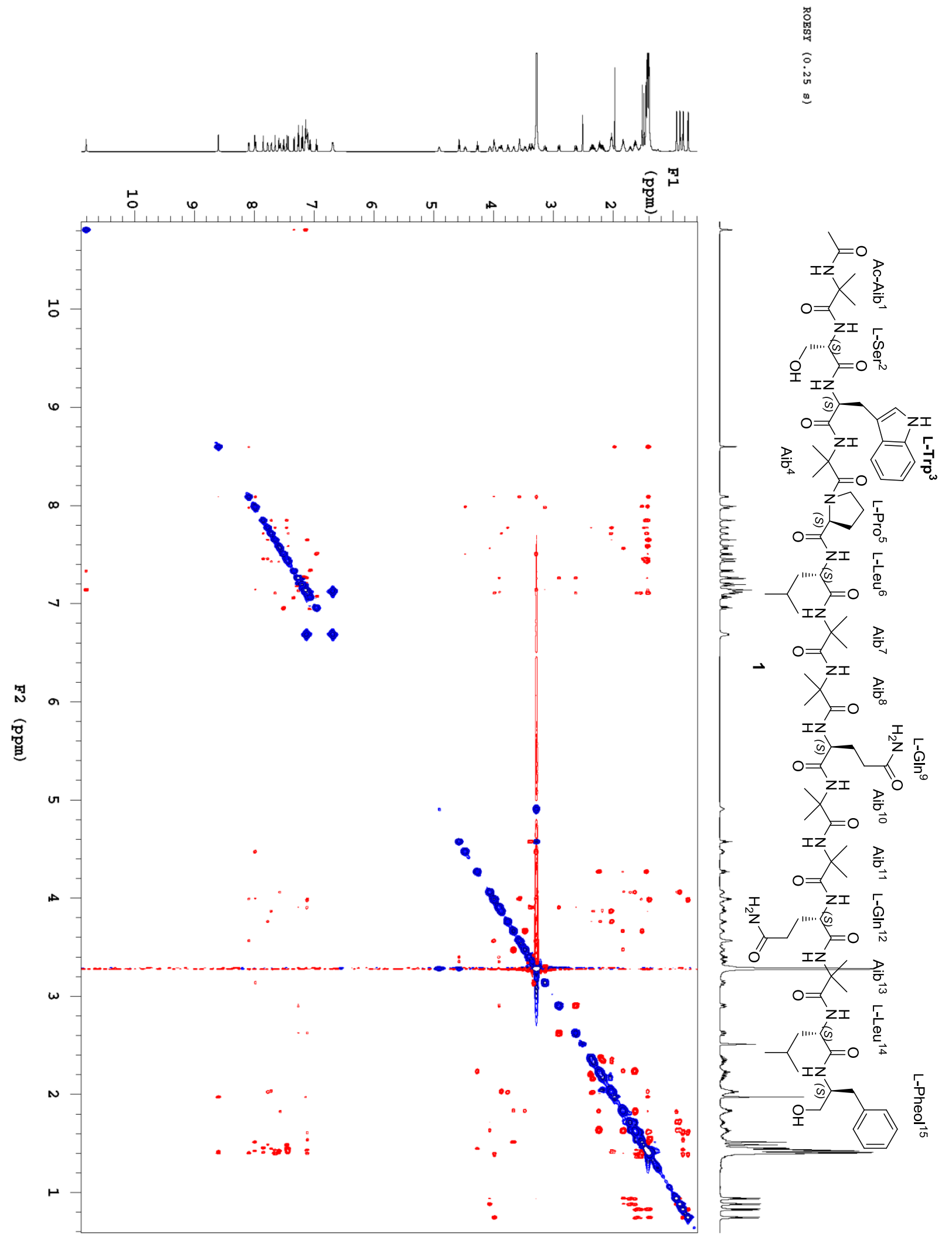


Fig. S8. ${ }^{1} \mathrm{H},{ }^{15} \mathrm{~N}$ HSQC spectrum of natural chilenopeptin A (1) $\left(600 \mathrm{MHz}\right.$, DMSO- $\left.d 6,40{ }^{\circ} \mathrm{C}\right)$




Fig. S9. ${ }^{1} \mathrm{H},{ }^{15} \mathrm{~N}$ HMBC spectrum of natural chilenopeptin A (1) $\left(600 \mathrm{MHz}, \mathrm{DMSO}-d 6,40{ }^{\circ} \mathrm{C}\right)$

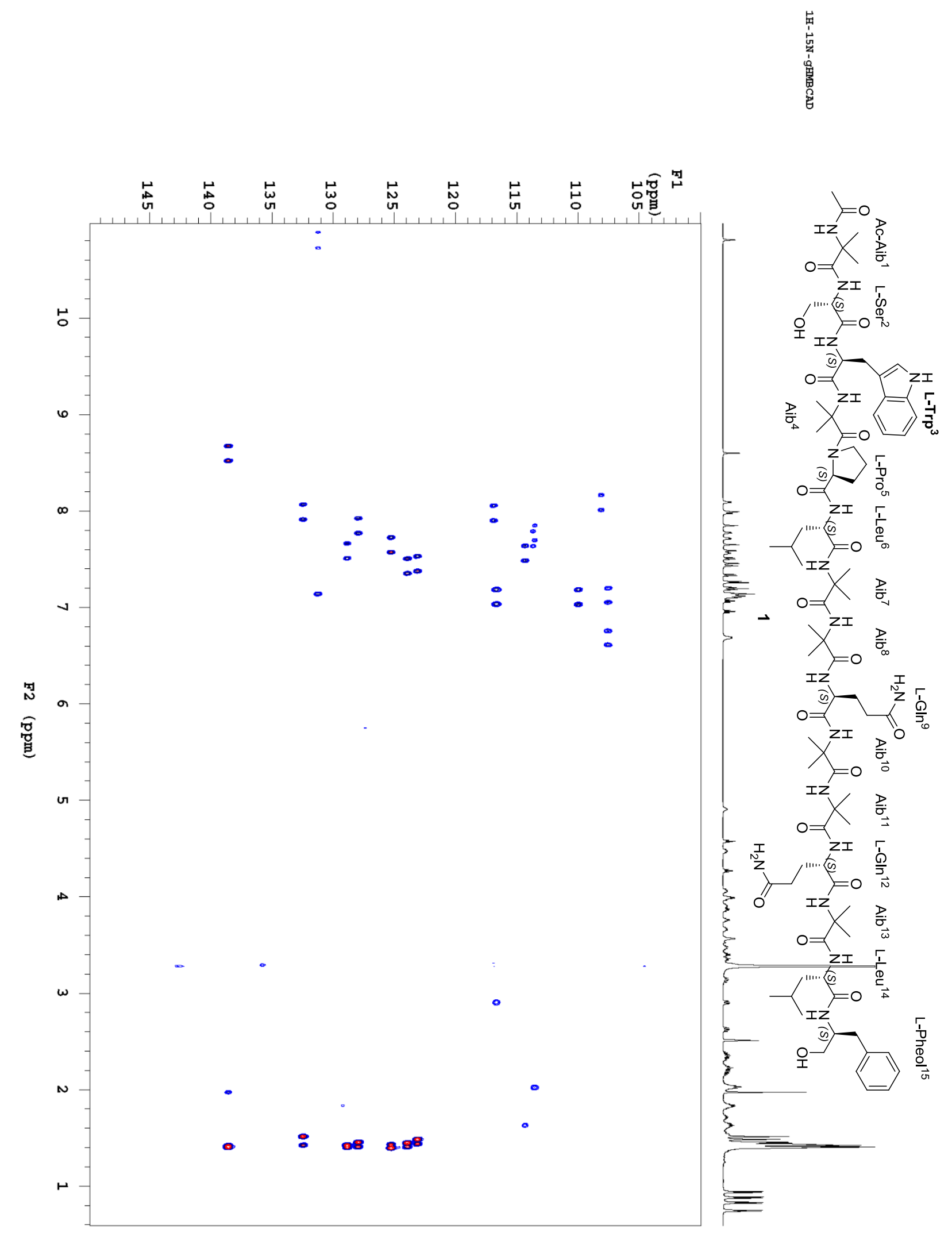


Fig. S10. UV spectrum of natural chilenopeptin A (1) in $\mathrm{MeOH}$

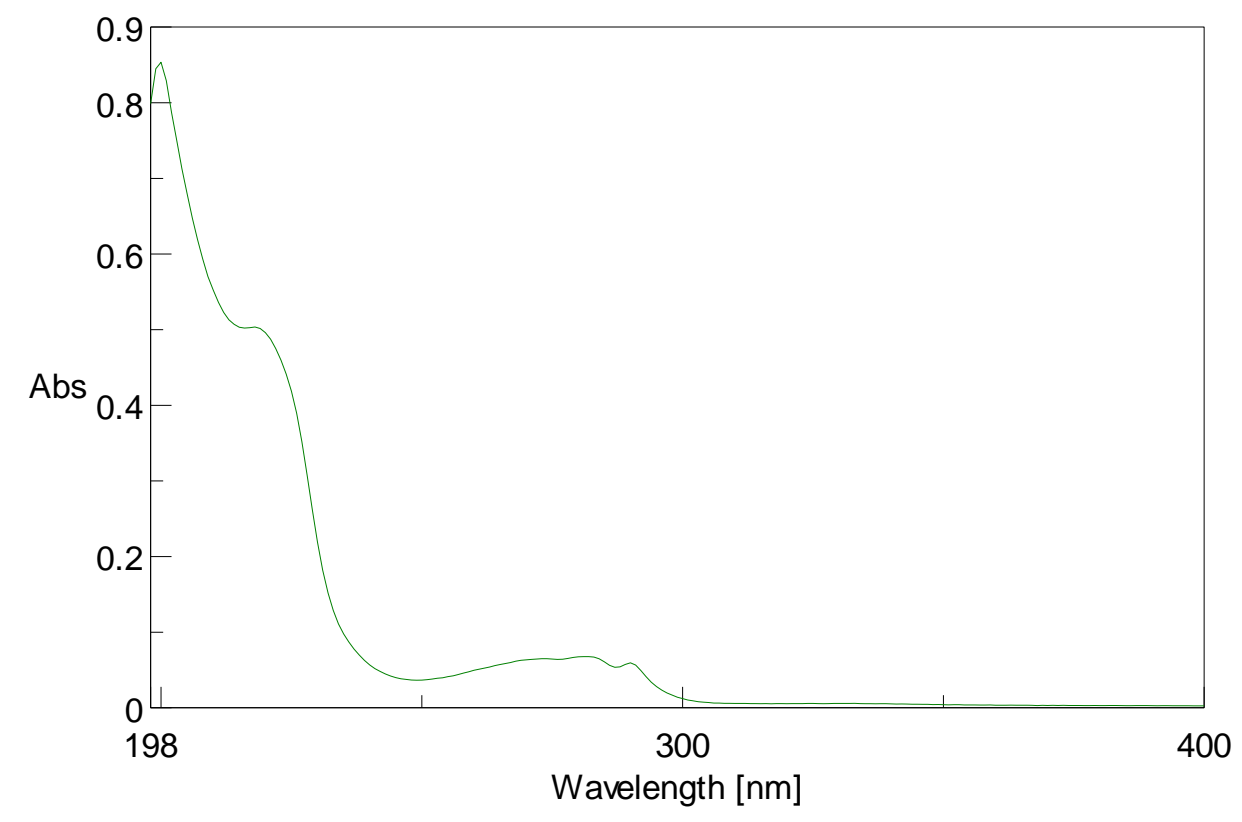


Fig. S11. ${ }^{1} \mathrm{H}$ NMR spectrum of natural chilenopeptin B (2) $\left(600 \mathrm{MHz}, \mathrm{DMSO}-d 6,40{ }^{\circ} \mathrm{C}\right)$

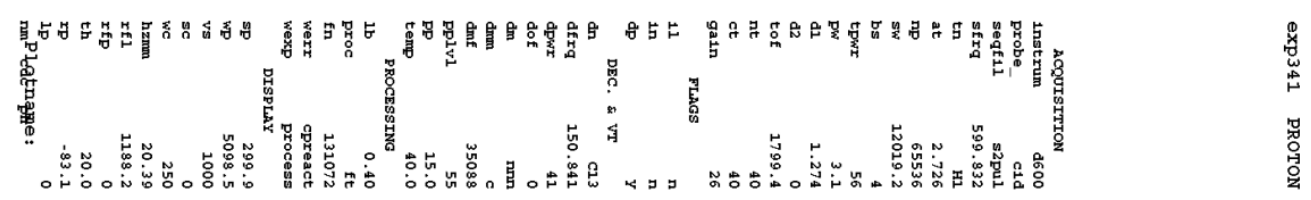



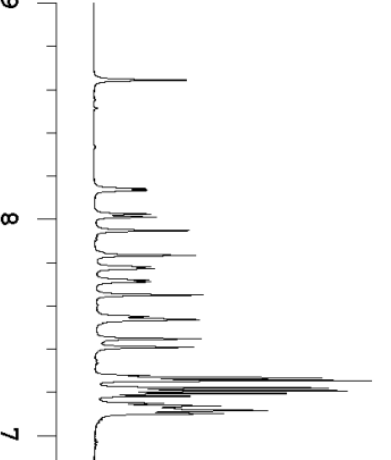



a


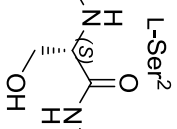
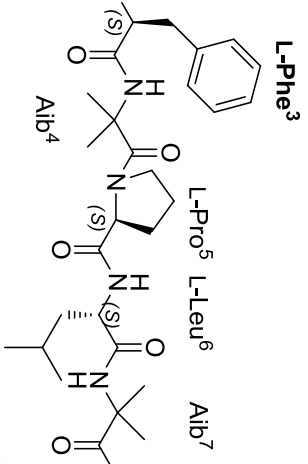

$X_{=0}^{z I} \stackrel{D}{\infty}_{\infty}$



$X_{=0}^{Z I} \overrightarrow{0}$

Iz

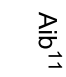
zI

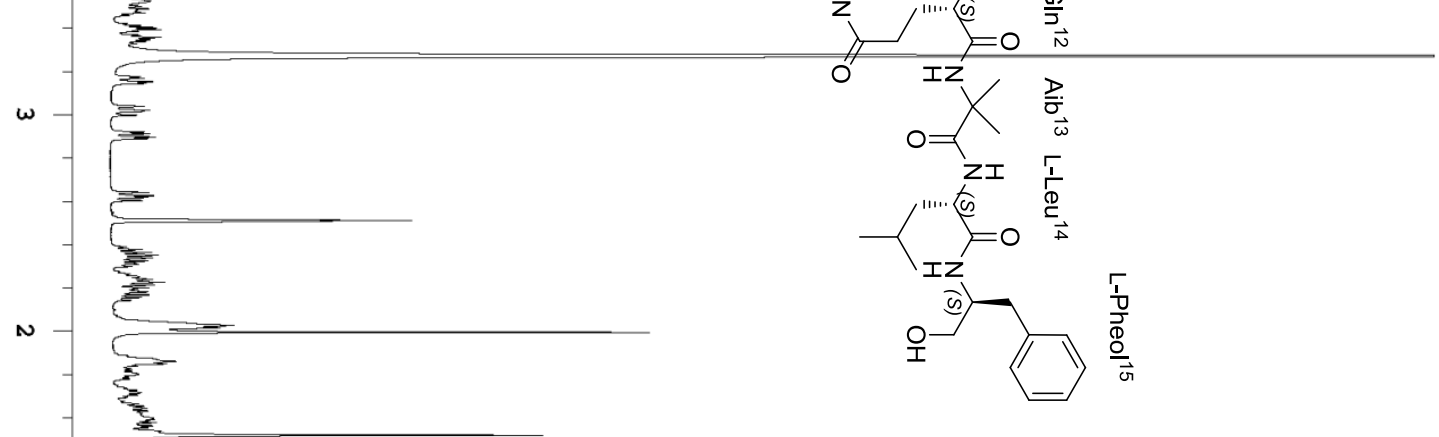

סृ

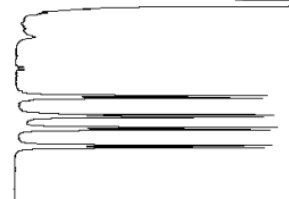


Fig. S12. ${ }^{13} \mathrm{C}$ NMR and DEPT-135 spectrum of natural chilenopeptin B (2) $(150 \mathrm{MHz}$, DMSO-d6, 40 ${ }^{\circ} \mathrm{C}$ )

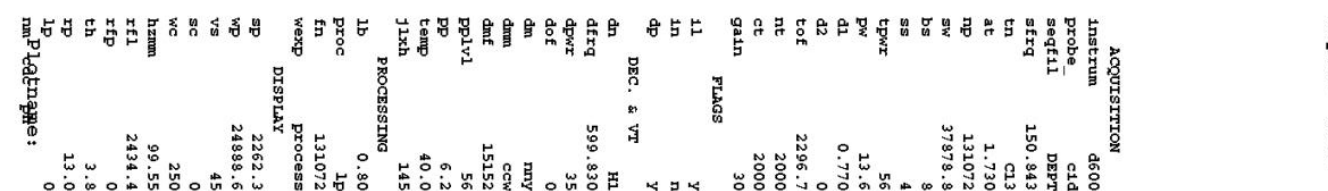

总
出
曷
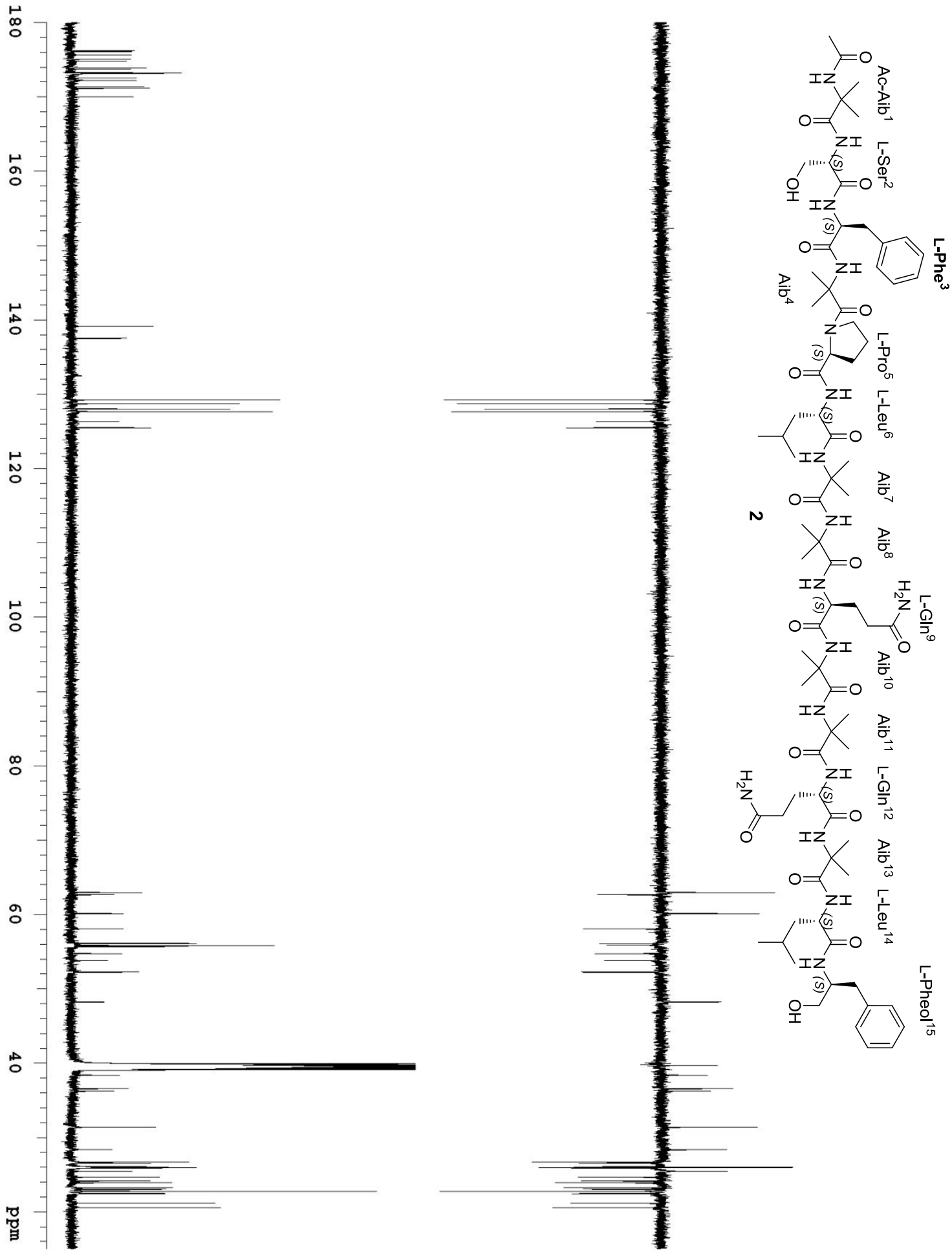
Fig. S13. UV spectrum of natural chilenopeptin B (2) in $\mathrm{MeOH}$




Fig. S14. ${ }^{1} \mathrm{H}$ NMR spectrum of synthetic chilenopeptin A (1) $\left(600 \mathrm{MHz}, \mathrm{DMSO}-d 6,40{ }^{\circ} \mathrm{C}\right)$
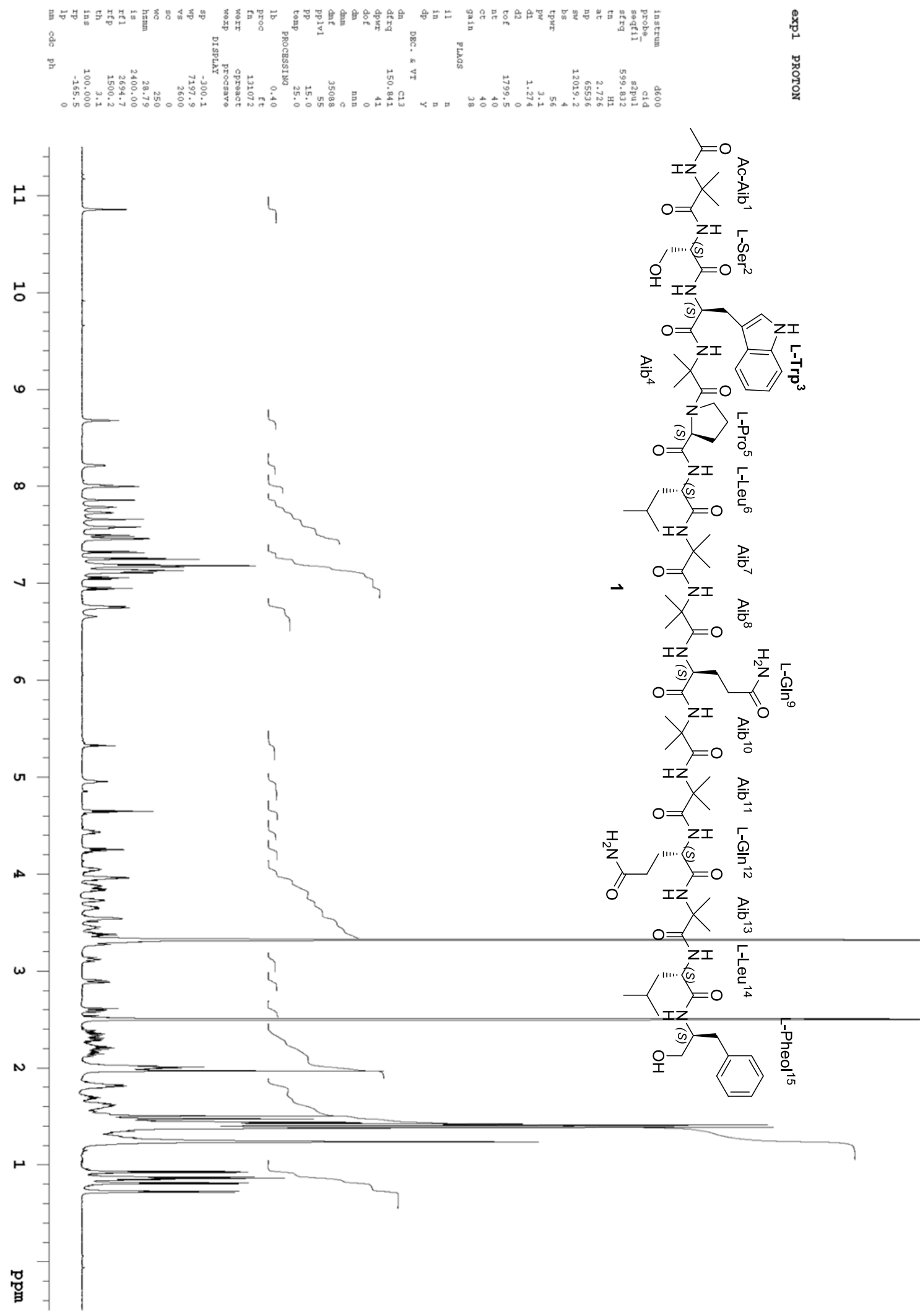
Fig. S15. ${ }^{13} \mathrm{C}$ NMR spectrum of synthetic chilenopeptin A (1) $\left(150 \mathrm{MHz}\right.$, DMSO- $\left.d 6,40{ }^{\circ} \mathrm{C}\right)$

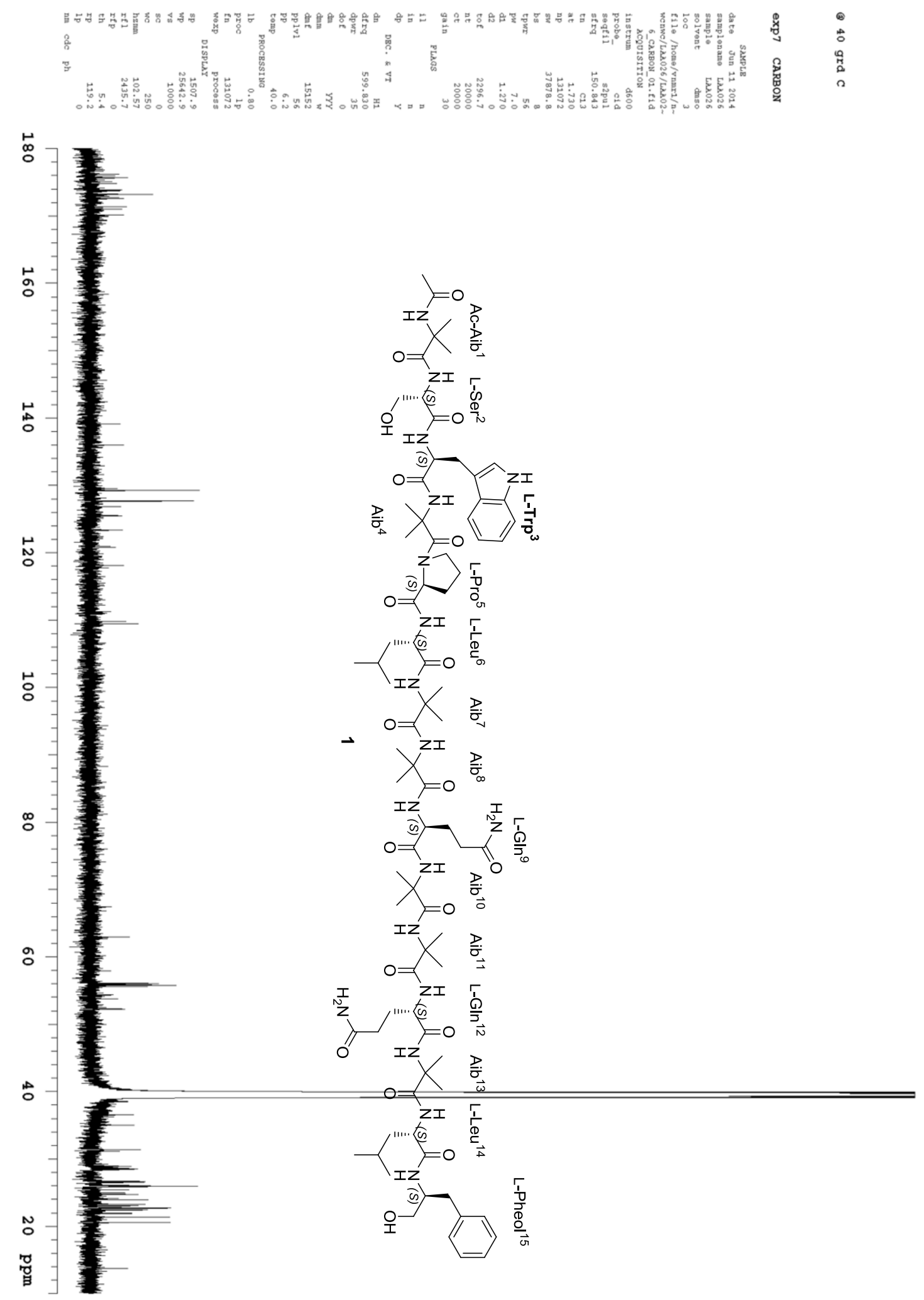


Fig. S16. ${ }^{1} \mathrm{H}$ NMR spectrum of synthetic chilenopeptin B (2) $\left(600 \mathrm{MHz}, \mathrm{DMSO}-d 6,40{ }^{\circ} \mathrm{C}\right)$
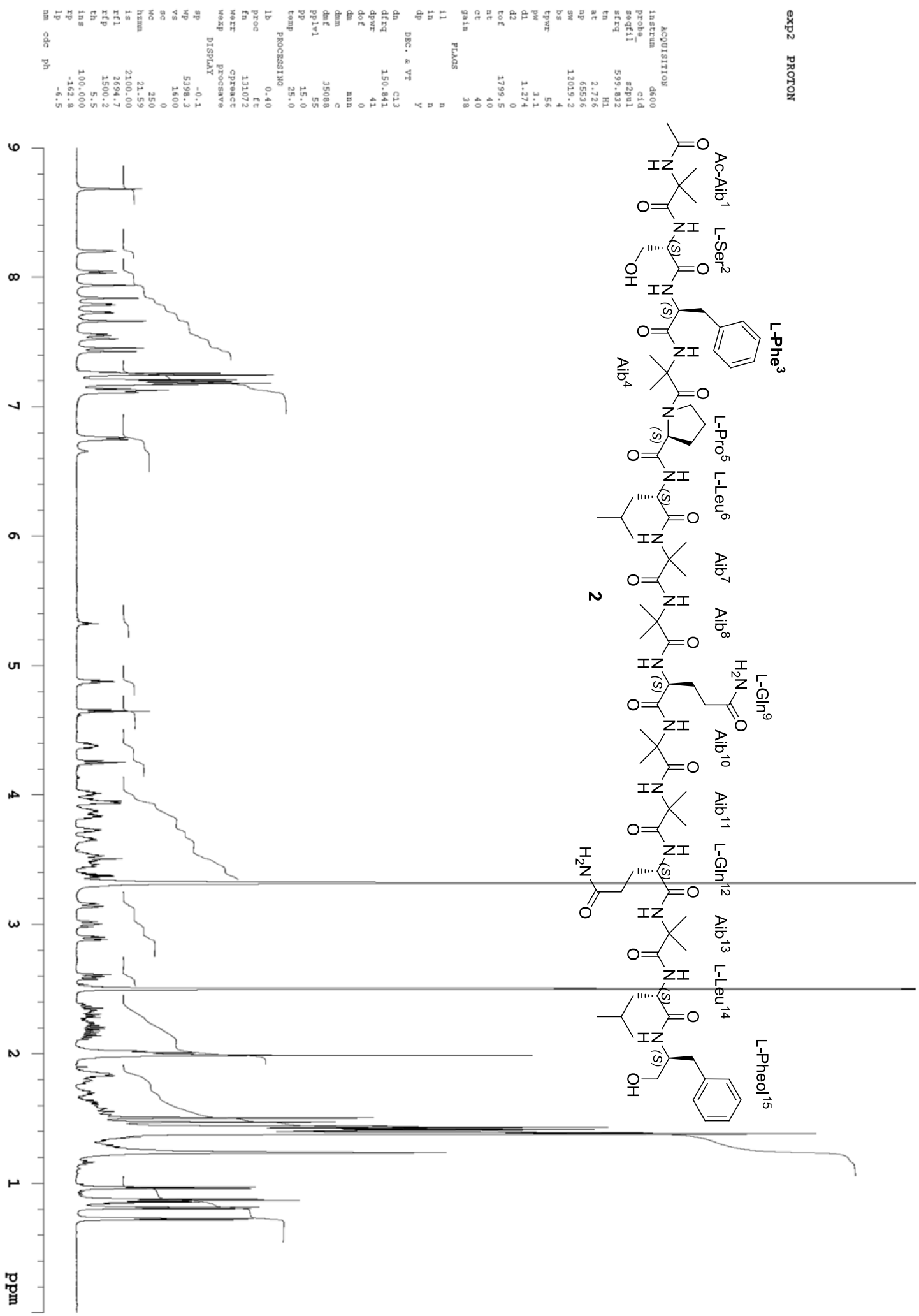
Fig. S17. ${ }^{13} \mathrm{C}$ NMR spectrum of synthetic chilenopeptin B (2) (150 MHz, DMSO- $d 6,40{ }^{\circ} \mathrm{C}$ )




Fig. S18. HPLC elution profiles of natural and synthetic chilenopeptins A (1) and B (2)

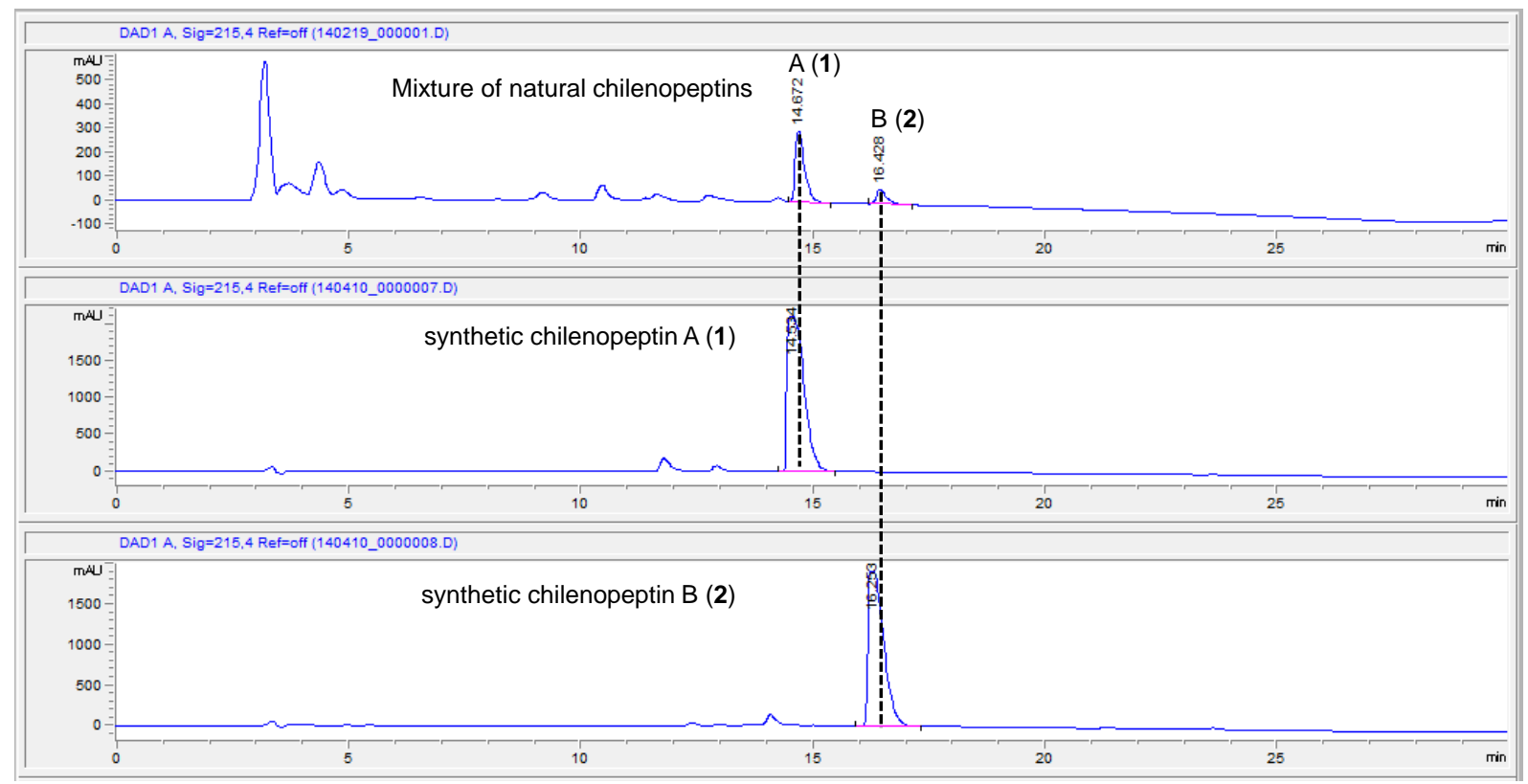


Fig. S19. Comparison of the amide and aromatic proton region in the ${ }^{1} \mathrm{H}$ NMR spectrum of natural and synthetic chilenopeptin A (1) $\left(600 \mathrm{MHz}, \mathrm{DMSO}-d 6,40{ }^{\circ} \mathrm{C}\right)$



synthetic chilenopeptin A (1)

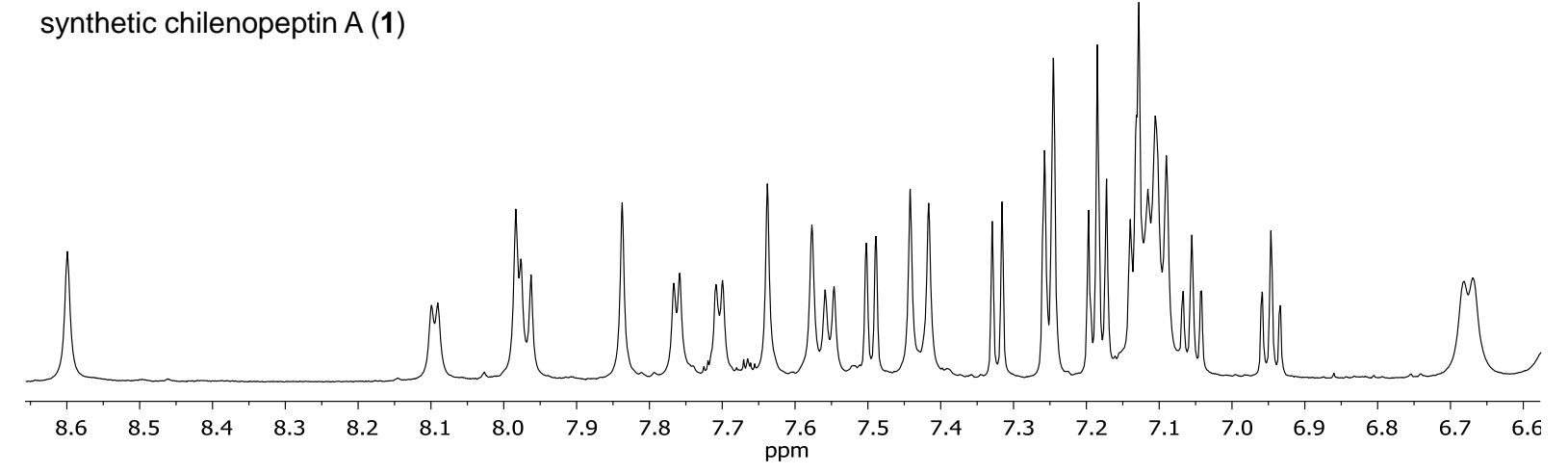

Fig. S20. Positive ion $\mathrm{MS}^{2}$ spectra of the $[\mathrm{M}+\mathrm{H}]^{+}$ions of natural and synthetic chilenopeptin A (1)

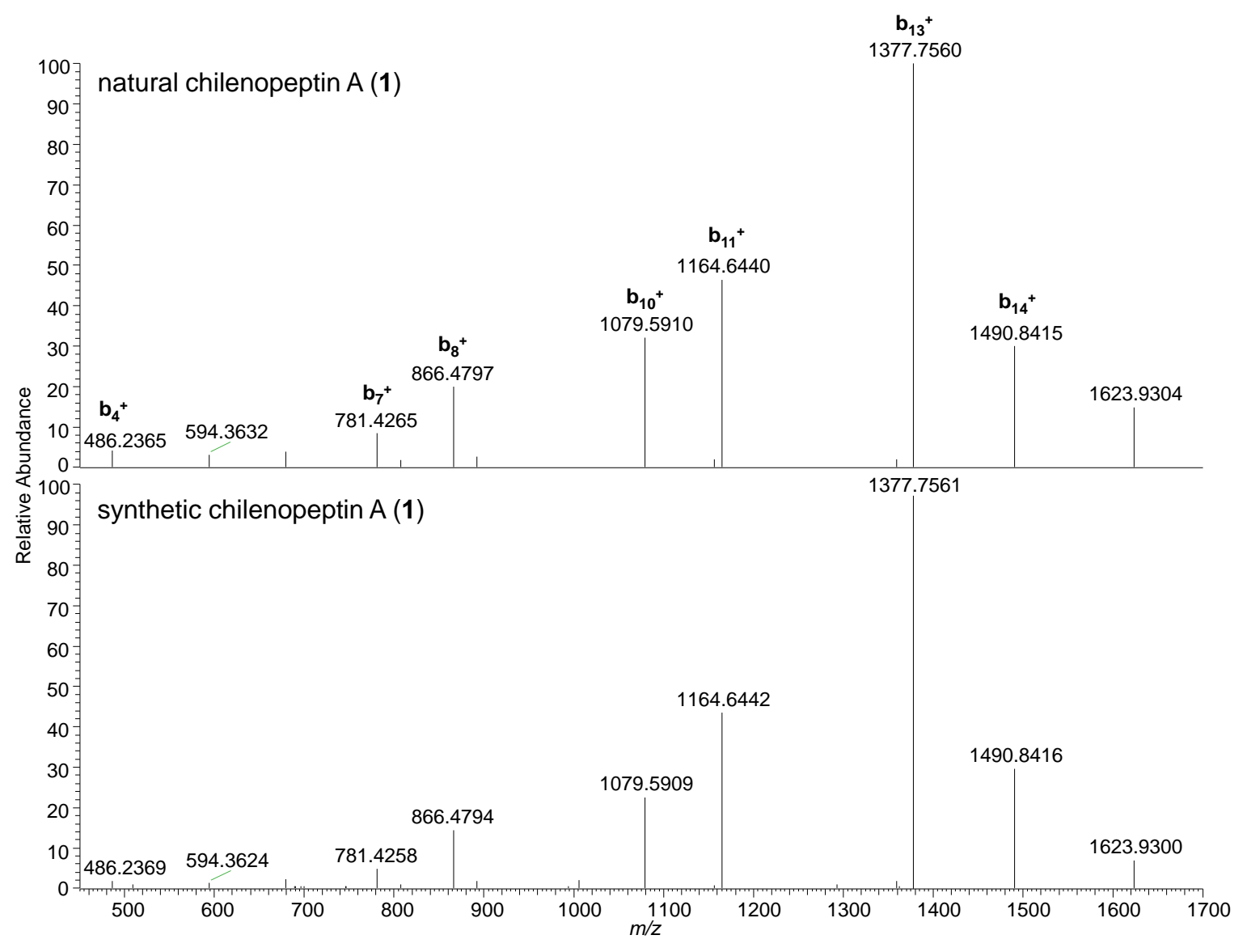


Fig. S21. CD spectra of natural (line) and synthetic (dots) chilenopeptin A (1) in $\mathrm{MeOH}$

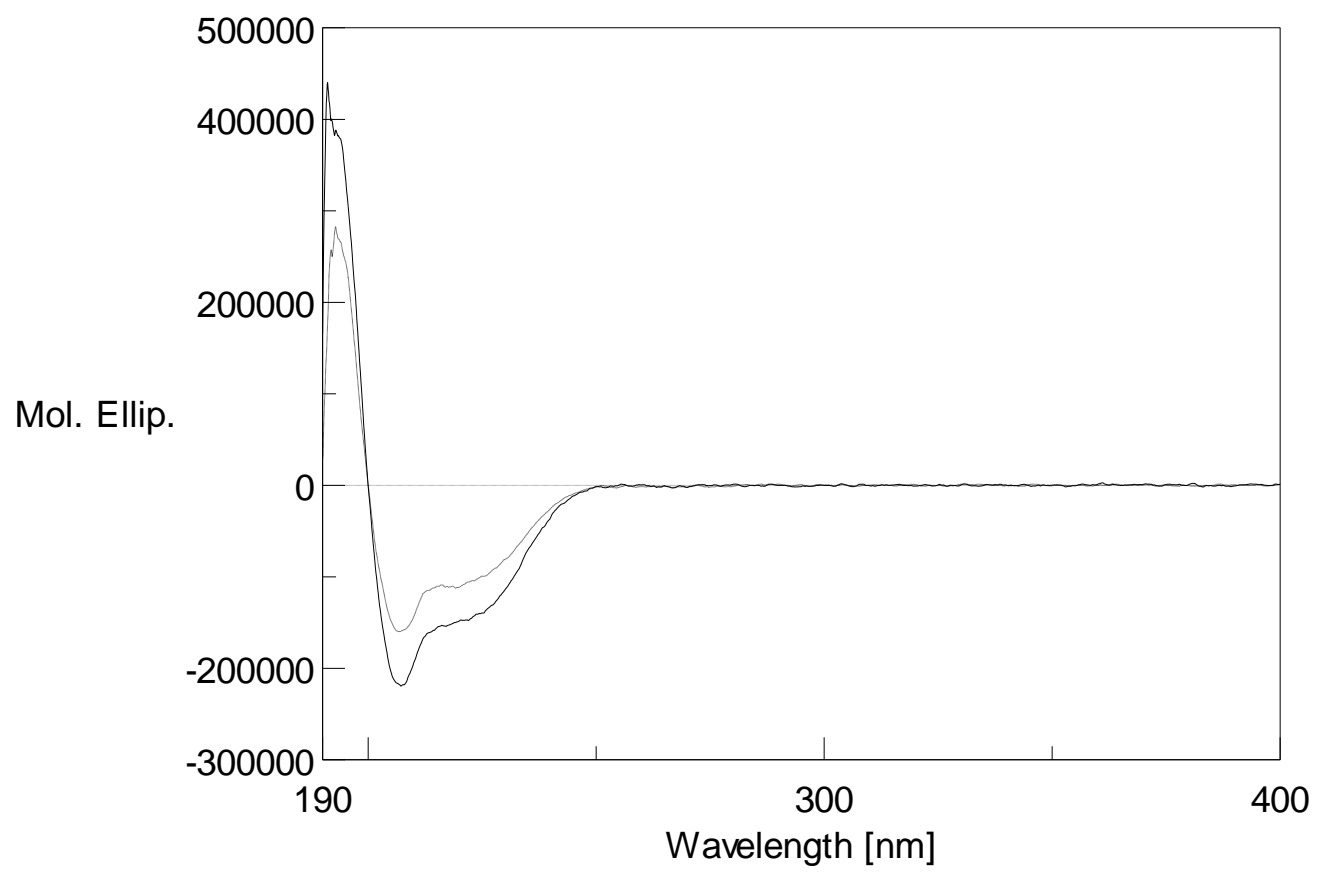


Fig. S22. Comparison of the carbonyl region in the ${ }^{13} \mathrm{C}$ NMR spectra of the synthetic and natural chilenopeptin B (2) $\left(150 \mathrm{MHz}, \mathrm{DMSO}-d 6,40{ }^{\circ} \mathrm{C}\right)$

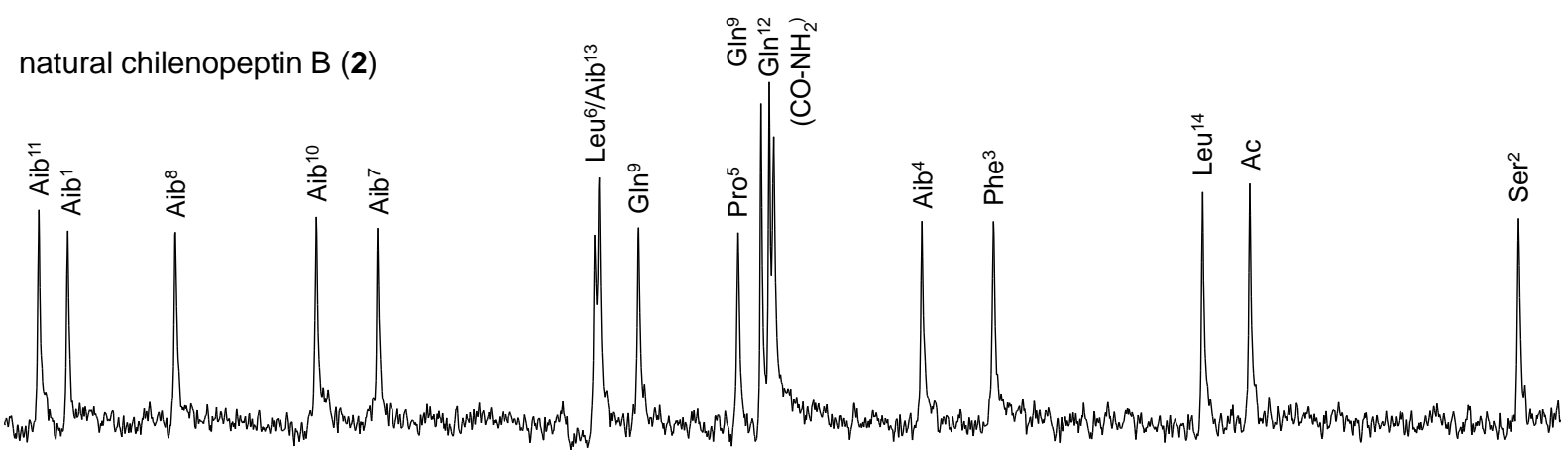

synthetic chilenopeptin B (2)



Fig. S23. Positive ion $\mathrm{MS}^{2}$ spectra of the $[\mathrm{M}+\mathrm{H}]^{+}$ions of natural and synthetic chilenopeptin B (2)

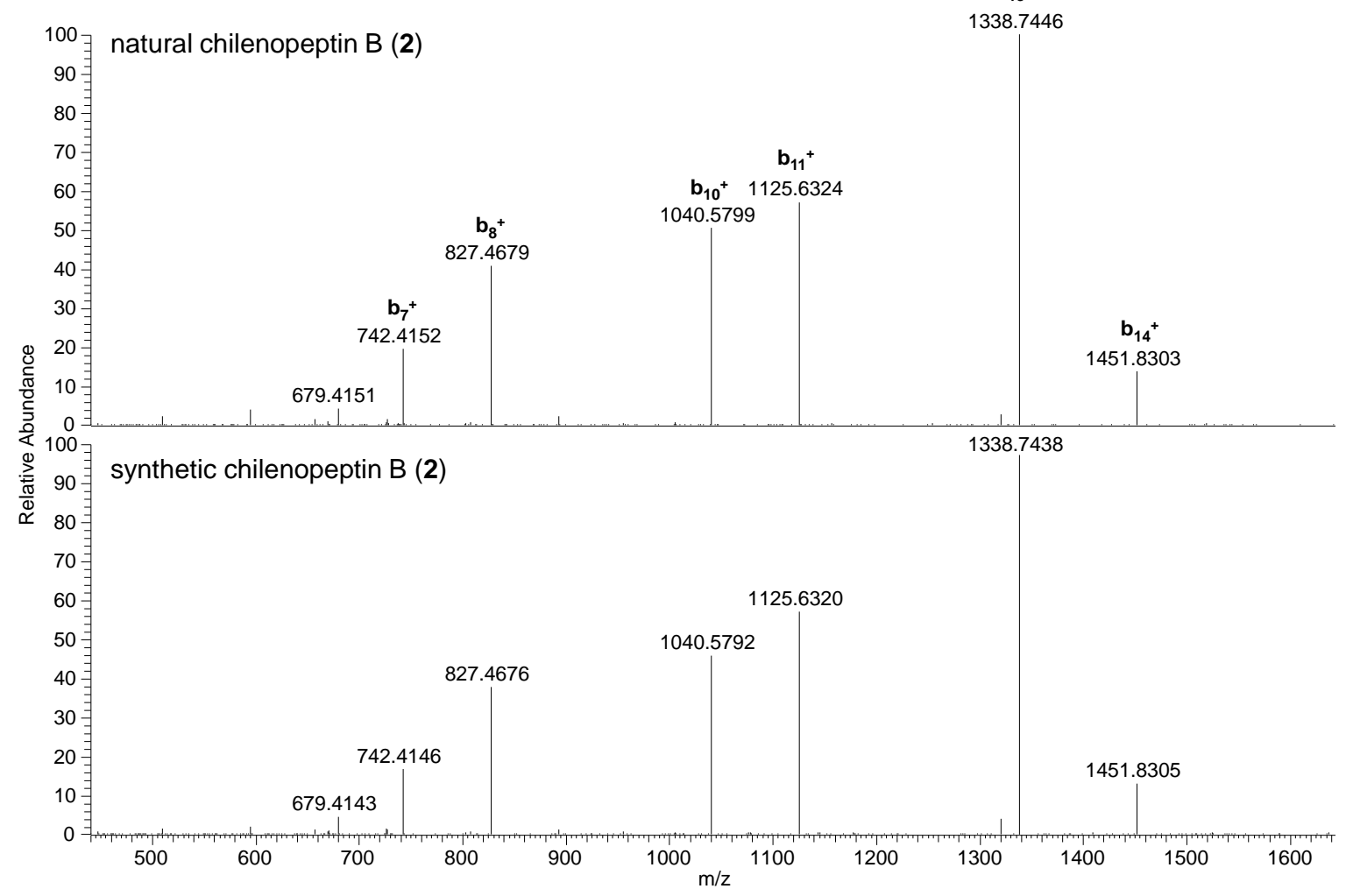


Fig. S24. CD spectra of natural (line) and synthetic (dots) chilenopeptin B (2) in $\mathrm{MeOH}$

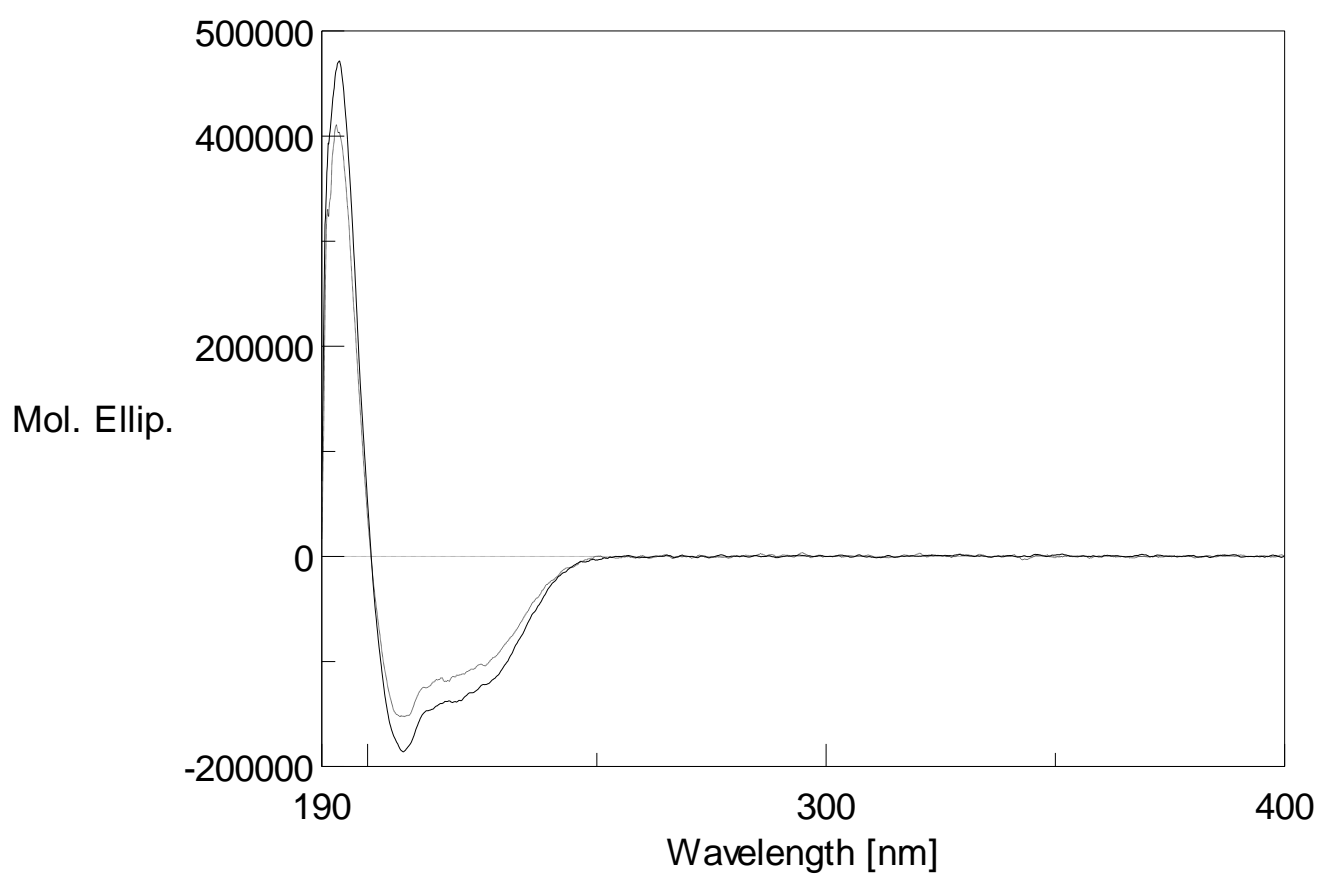


Fig. S25. ${ }^{1} \mathrm{H}$ NMR spectrum of tylopeptin A (3) $\left(600 \mathrm{MHz}\right.$, DMSO- $\left.d 6,40{ }^{\circ} \mathrm{C}\right)$

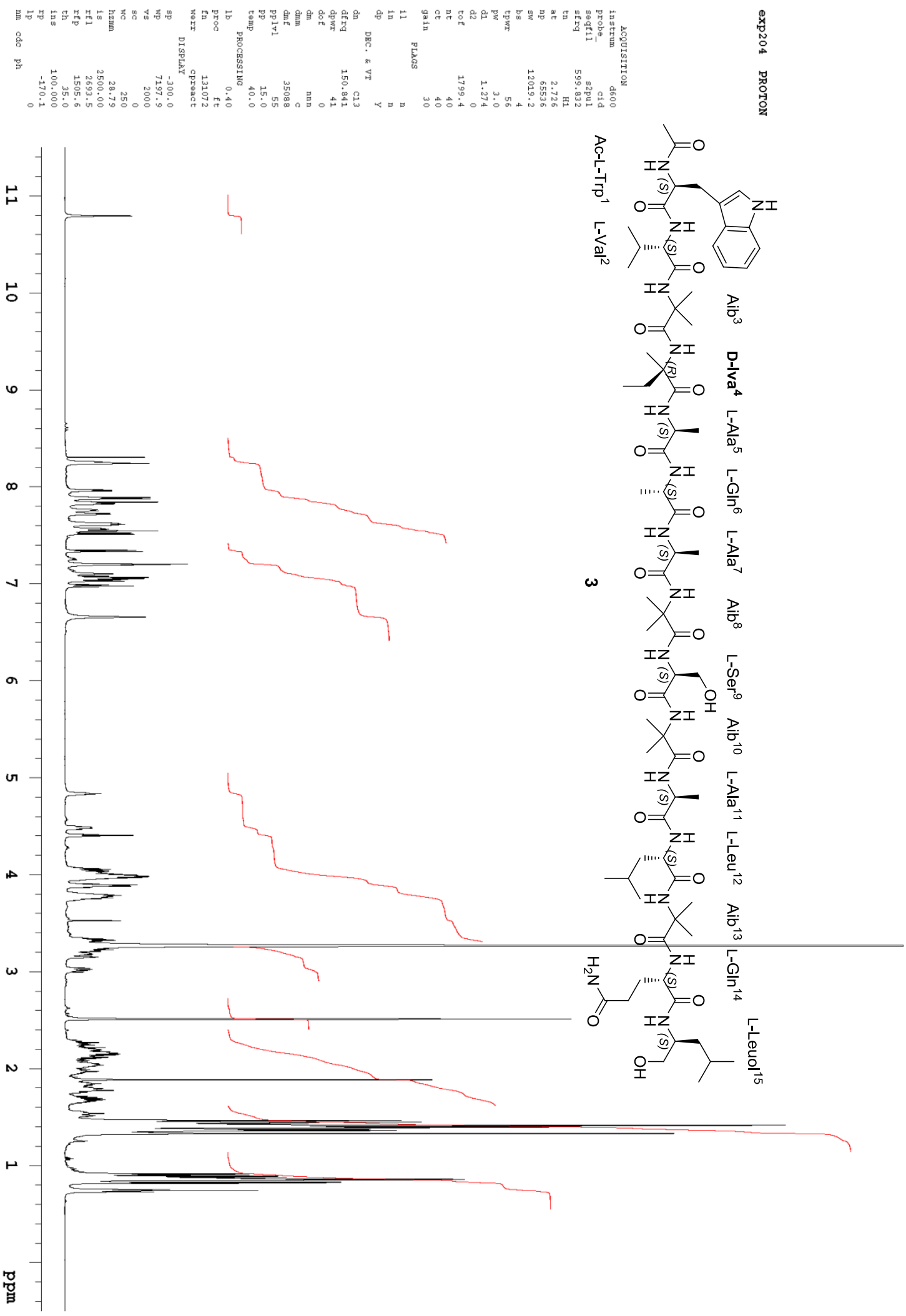


Fig. S26. ${ }^{13} \mathrm{C}$ NMR spectrum of tylopeptin A (3) $\left(150 \mathrm{MHz}\right.$, DMSO- $\left.d 6,40{ }^{\circ} \mathrm{C}\right)$

Fig. S27. ${ }^{1} \mathrm{H}$ NMR spectrum of tylopeptin B (4) $\left(600 \mathrm{MHz}\right.$, DMSO- $\left.d 6,40{ }^{\circ} \mathrm{C}\right)$

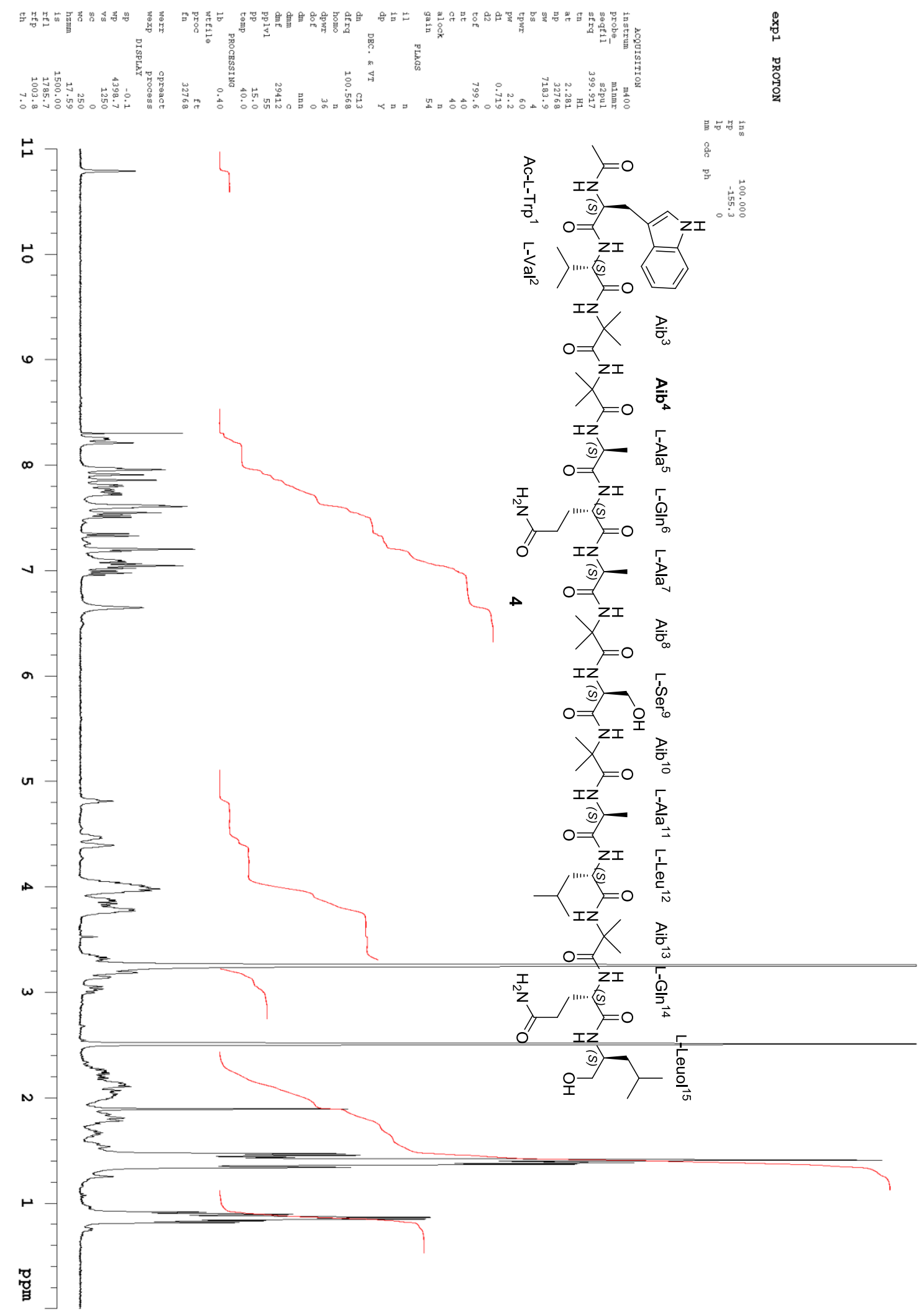


Fig. S28. ${ }^{13} \mathrm{C}$ NMR spectrum of tylopeptin B (4) $\left(150 \mathrm{MHz}\right.$, DMSO- $\left.d 6,40{ }^{\circ} \mathrm{C}\right)$
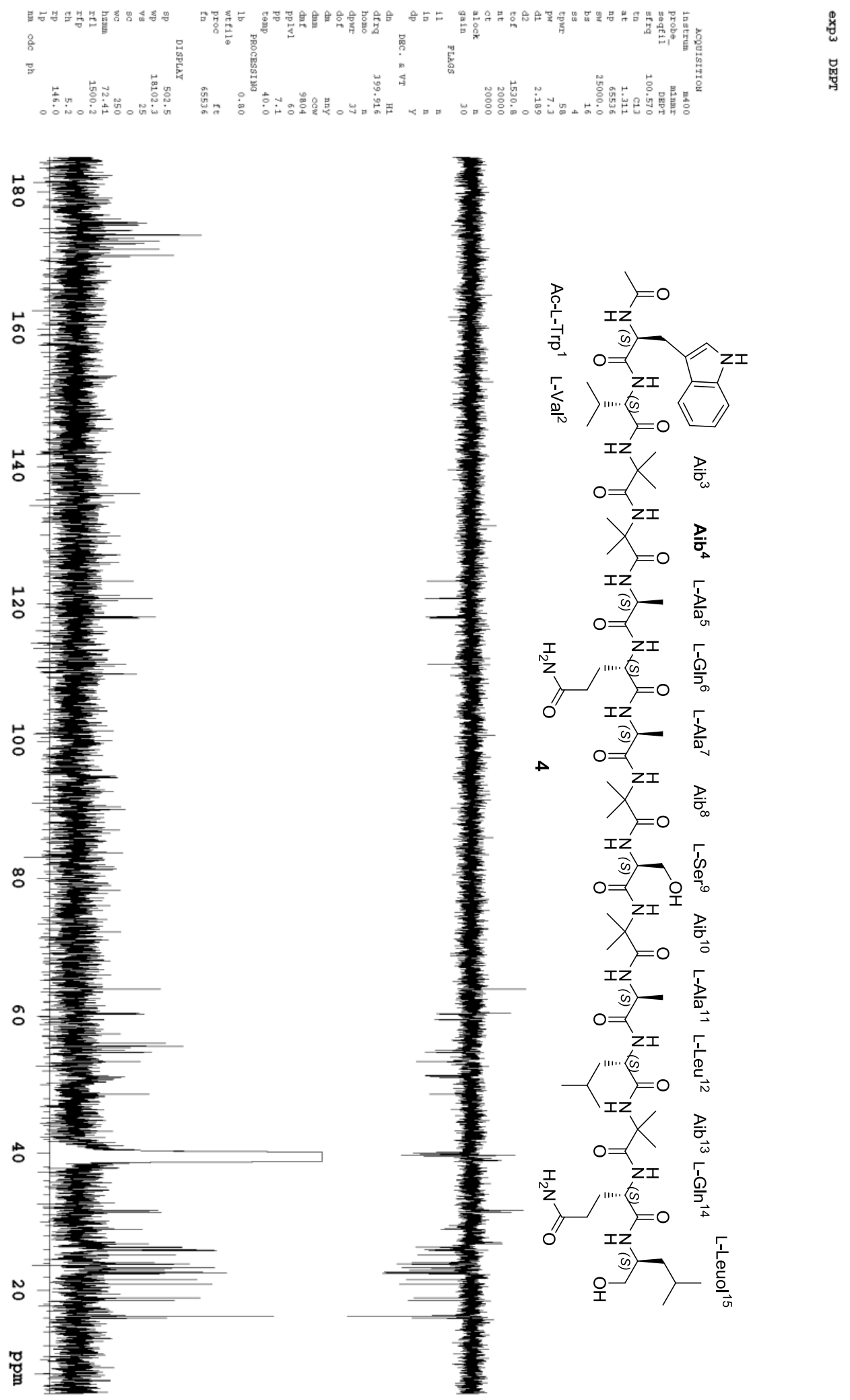
Table S1. Protocol of solid-phase peptide synthesis

\begin{tabular}{|c|c|}
\hline Prepare & \\
\hline 1 Memo & ResPep SL version, $100 \mu \mathrm{mol}$ peptide synthesis, 3-columns \\
\hline 2 RinseNeedle & $2000 / 2500 \mu 1$ \\
\hline 3 WashColumns & $3200 \mu 1$, Reservoir ->Peptides \\
\hline 4 WashColumns & $3200 \mu 1$, DCM ->Peptides, $2 x$ \\
\hline 5 WashColumns & $3200 \mu 1$, Reservoir $->$ Peptides, $2 \mathrm{x}$ \\
\hline 6 RinseNeedle & $500 / 1500 \mu 1$ \\
\hline 7 Extract & $20 \mathrm{~s}$ \\
\hline \multicolumn{2}{|l|}{ Cycle: 1 -> 14} \\
\hline 8 Deprotection & $1800 \mu 1$, Piperidine ->Peptides \\
\hline 9 Deprotection & $1800 \mu 1$, Piperidine ->Peptides \\
\hline 10 Agitate & 700 / $300 \mu \mathrm{l}, 00: 08 \mathrm{hh}: \mathrm{mm}$ \\
\hline 11 RinseNeedle & $1000 / 2000 \mu \mathrm{l}$ \\
\hline 12 WashColumns & $3200 \mu 1$, Reservoir ->Peptides, $2 x$ \\
\hline 13 WashColumns & $2500 \mu 1$, Reservoir ->Peptides \\
\hline 14 WashColumns & $3200 \mu$ l, Reservoir ->Peptides, 3x \\
\hline 15 RinseNeedle & $1000 / 1500 \mu \mathrm{l}$ \\
\hline 16 Activation/Coupling & $808+250+10+833->$ Peptides \\
\hline 17 Agitate & 700 / $300 \mu$ l, 00:18 hh:mm \\
\hline 18 Capping & $1800 \mu 1$, CapMixture ->Peptides \\
\hline 19 WashColumns & $3200 \mu 1$, Reservoir ->Peptides \\
\hline 20 WashColumns & $2500 \mu 1$, Reservoir ->Peptides \\
\hline 21 WashColumns & $3200 \mu 1$, Reservoir ->Peptides, 3x \\
\hline \multicolumn{2}{|l|}{ Final } \\
\hline 22 Deprotection & $1800 \mu 1$, Piperidine ->Peptides \\
\hline 23 Deprotection & $1800 \mu 1$, Piperidine ->Peptides \\
\hline 24 Agitate & 700 / $300 \mu$ l, 00:10 hh:mm \\
\hline 25 Deprotection & $2000 \mu$ l, Piperidine ->Peptides \\
\hline 26 Agitate & 700 / $300 \mu \mathrm{l}, 00: 12 \mathrm{hh}: \mathrm{mm}$ \\
\hline 27 RinseNeedle & $1000 / 2000 \mu \mathrm{l}$ \\
\hline 28 WashColumns & $3200 \mu 1$, Reservoir $->$ Peptides, $3 x$ \\
\hline 29 WashColumns & $2500 \mu 1$, Reservoir ->Peptides \\
\hline 28 WashColumns & $3200 \mu \mathrm{l}$, Reservoir $->$ Peptides, 5x \\
\hline 29 WashColumns & $4000 \mu 1$, DCM ->Peptides \\
\hline 30 WashColumns & $3200 \mu 1$, DCM ->Peptides \\
\hline 31 RinseNeedle & $1000 / 2500 \mu l$ \\
\hline 32 Extract & $60 \mathrm{~s}$ \\
\hline
\end{tabular}


Table S2. Positive and negative ion HRESIMS ${ }^{\mathrm{n}}$ data of chilenopeptins A (1) and B (2)

\begin{tabular}{|c|c|c|}
\hline cpd & $(+) /(-)$ scan mode $[m / z(\mathrm{NCE}$ in $\%)]$ & $m / z$ (fragment ion, relative intensity in $\%$, error in $\mathrm{ppm}$ ) \\
\hline 1 & $(+)$ full MS & $1641.9368\left([\mathbf{M}+\mathbf{H}]^{+}, 21,0.3\right), 821.4735\left([\mathbf{M}+\mathbf{2 H}]^{2+}, 100,2.0\right)$ \\
\hline 1 & $(+) \mathrm{MS}^{2}[821.5(55)]$ & $\begin{array}{l}1156.7105\left(\mathbf{y}_{11}{ }^{+}, 90,1.4\right), 1005.6108\left(\mathbf{y}_{11}{ }^{+}-\mathbf{a a}(\mathbf{1 5}), 45,1.8\right), 892.5265\left(\mathbf{y}_{11}{ }^{+}-\right. \\
\mathbf{a a}(\mathbf{1 4 - 1 5}), 26,1.6), 486.2355\left(\mathbf{b}_{\mathbf{4}}^{+}, 100,1.6\right), 401.1827\left(\mathbf{b}_{\mathbf{3}}^{+}, 30,2.0\right)\end{array}$ \\
\hline 1 & $(+) \mathrm{MS}^{2}[1642.0(45)]$ & $\begin{array}{l}1490.8415\left(\mathbf{b}_{14}^{+}, 29,3.3\right), 1377.7560\left(\mathbf{b}_{13}{ }^{+}, 100,2.5\right), 1292.7035\left(\mathbf{b}_{12}^{+},<1,2.9\right), \\
1164.6440\left(\mathbf{b}_{11}^{+}, 46,2.4\right), 1079.5910\left(\mathbf{b}_{10}^{+}, 31,2.4\right), 994.5335\left(\mathbf{b}_{9}^{+},<1,2.1\right), \\
866.4797\left(\mathbf{b}_{\mathbf{8}}^{+}, 20,3.0\right), 781.4265\left(\mathbf{b}_{7}^{+}, 8,2.8\right), 696.3747\left(\mathbf{b}_{\mathbf{6}}^{+},<1,4.6\right)\end{array}$ \\
\hline 1 & $(+) \mathrm{MS}^{3}[1642.0(55) \rightarrow \mathbf{1 1 6 5 . 0}(\mathbf{4 5})]$ & $\begin{array}{l}1079.5907\left(\mathbf{b}_{10}^{+}, 100,2.1\right), 866.4788\left(\mathbf{b}_{\mathbf{8}}^{+}, 89,2.0\right), 781.4264\left(\mathbf{b}_{7}^{+}, 48,2.7\right), \\
696.3777\left(\mathbf{b}_{\mathbf{6}}^{+}, 4,8.9\right), 486.2359\left(\mathbf{b}_{\mathbf{4}}^{+}, 72,2.5\right), 401.1826\left(\mathbf{b}_{\mathbf{3}}^{+}, 5,1.7\right)\end{array}$ \\
\hline 1 & $(+) \mathrm{MS}^{3}[821.5(55) \rightarrow \mathbf{1 1 5 7 . 0}(\mathbf{5 5})]$ & $\begin{array}{l}1005.6107\left(\mathbf{y}_{\mathbf{1 1}}{ }^{+}-\mathbf{a a}(\mathbf{1 5}), 54,1.6\right), 892.5262\left(\mathbf{y}_{11}{ }^{+}-\mathbf{a a}(\mathbf{1 4 - 1 5}), 100,1.2\right), 807.4731 \\
\left(\mathbf{y}_{\mathbf{1 1}}{ }^{+}-\mathbf{a a}(\mathbf{1 3 - 1 5}), 49,1.0\right), 679.4144\left(\mathbf{y}_{\mathbf{1 1}}{ }^{+}-\mathbf{a a}(\mathbf{1 2 - 1 5}), 72,1.0\right), 594.3617\left(\mathbf{y}_{\mathbf{1 1}}{ }^{+}-\right. \\
\mathbf{a a}(\mathbf{1 1 - 1 5}), 67,1.2), 509.3089\left(\mathbf{y}_{\mathbf{1 1}}{ }^{+}-\mathbf{a a}(\mathbf{1 0 - 1 5}), 33,1.4\right), 381.2498\left(\mathbf{y}_{11}{ }^{+}-\mathbf{a a}(\mathbf{9}-\right. \\
\mathbf{1 5}), 12,0.5)\end{array}$ \\
\hline 1 & $(+) \mathrm{MS}^{3}[821.5(55) \rightarrow \mathbf{4 8 6 . 0}(\mathbf{6 5})]$ & $401.1824\left(\mathbf{b}_{3}^{+}, 56,1.2\right), 215.1039\left(\mathbf{b}_{2}^{+}, 4,6.0\right)$ \\
\hline 1 & (-) full MS & 1685.9343 ([M-H+HCOOH]', 100, 4.2), 1639.9235 ([M-H]', 7, 1.1) \\
\hline 1 & $(-) \mathrm{MS}^{2}[\mathbf{1 6 4 0 . 0}(45)]$ & $1609.9102\left(\mathbf{v}_{15}, 100,0.6\right)$ \\
\hline 1 & $(-) \mathrm{MS}^{3}[1640.0(55) \rightarrow \mathbf{1 6 1 0 . 0}(\mathbf{6 5})]$ & $\begin{array}{l}1482.8400\left(\mathbf{v}_{\mathbf{1 4}}^{-},<1,5.3\right), 1425.8292\left(\mathbf{y}_{\mathbf{1 3}}^{-}, 2,2.0\right), 1239.7488\left(\mathbf{y}_{\mathbf{1 2}}^{-}, 1,1.4\right), \\
1154.6945\left(\mathbf{y}_{\mathbf{1 1}}^{-}, 100,0.2\right), 1057.6410\left(\mathbf{y}_{\mathbf{1 0}}^{-}, 1,0.5\right), 944.5580\left(\mathbf{y}_{\mathbf{9}}^{-}, 2,0.5\right), \\
859.5054\left(\mathbf{y}_{\mathbf{8}}^{-}, 6,0.8\right), 774.4524\left(\mathbf{y}_{7}^{-}, 11,0.6\right), 646.3939\left(\mathbf{y}_{\mathbf{6}}^{-}, 5,0.8\right)\end{array}$ \\
\hline 1 & $(-) \mathrm{MS}^{3}[1640.0(55) \rightarrow \mathbf{1 1 5 5 . 0}(\mathbf{5 5})]$ & $\begin{array}{l}1057.6478\left(\mathbf{y}_{10}^{-}, 1,6.0\right), 944.5600\left(\mathbf{y}_{\mathbf{9}}^{-}, 22,2.6\right), 859.5060\left(\mathbf{y}_{\mathbf{8}}^{-}, 76,1.5\right), \\
774.4520\left(\mathbf{y}_{7}^{-}, 100,0.1\right), 646.3943\left(\mathbf{y}_{\mathbf{6}}^{-}, 58,1.4\right), 561.3411\left(\mathbf{y}_{\mathbf{5}}^{-}, 43,0.9\right) \\
476.2884\left(\mathbf{y}_{\mathbf{4}}^{-}, 30,1.3\right), 348.2279\left(\mathbf{y}_{\mathbf{3}^{-}}, 4,4.0\right)\end{array}$ \\
\hline 2 & (+) full MS & $1602.9260\left([\mathbf{M}+\mathbf{H}]^{+}, 18,0.4\right), 801.9671\left([\mathbf{M}+\mathbf{2 H}]^{2+}, 100,0.9\right)$ \\
\hline 2 & (+) $\mathrm{MS}^{2}[\mathbf{8 0 2 . 0}(55)]$ & $\begin{array}{l}1156.7098\left(\mathbf{y}_{11}^{+}, 75,0.8\right), 1005.6101\left(\mathbf{y}_{11}^{+}-\mathbf{a a}(\mathbf{1 5}), 45,1.0\right), 892.5259\left(\mathbf{y}_{\mathbf{1 1}}{ }^{+}-\right. \\
\mathbf{a a}(\mathbf{1 4 - 1 5}), 31,0.9), 447.2243\left(\mathbf{b}_{\mathbf{4}}^{+}, 100,4.0\right), 362.1715\left(\mathbf{b}_{\mathbf{3}}^{+}, 37,1.4\right)\end{array}$ \\
\hline 2 & $(+) \mathrm{MS}^{2}[1603.0(65)]$ & $\begin{array}{l}1451.8303\left(\mathbf{b}_{14}{ }^{+}, 15,3.2\right), 1338.7446\left(\mathbf{b}_{13}{ }^{+}, 100,2.2\right), 1253.6842\left(\mathbf{b}_{12}{ }^{+}, 1,3.7\right), \\
1125.6324\left(\mathbf{b}_{11}^{+}, 57,1.9\right), 1040.5799\left(\mathbf{b}_{10}^{+}, 55,2.3\right), 955.5270\left(\mathbf{b}_{\mathbf{9}}^{+}, 1,2.4\right), \\
827.4679\left(\mathbf{b}_{\mathbf{8}}^{+}, 42,2.1\right), 742.4152\left(\mathbf{b}_{7}^{+}, 22,2.4\right), 657.3608\left(\mathbf{b}_{\mathbf{6}}^{+}, 2,0.3\right)\end{array}$ \\
\hline 2 & $(+) \mathrm{MS}^{3}[1603.0(55) \rightarrow \mathbf{1 1 2 6 . 0}(\mathbf{4 5})]$ & $\begin{array}{l}1040.5807\left(\mathbf{b}_{10}^{+}, 99,3.1\right), 827.4687\left(\mathbf{b}_{\mathbf{8}}^{+}, 100,3.0\right), 742.4158\left(\mathbf{b}_{7}^{+}, 58,3.2\right), \\
657.3605\left(\mathbf{b}_{\mathbf{6}}^{+}, 7,0.2\right), 447.2243\left(\mathbf{b}_{\mathbf{4}}^{+}, 49,1.1\right), 362.1725\left(\mathbf{b}_{\mathbf{3}}^{+}, 8,4.1\right)\end{array}$ \\
\hline 2 & $(+) \mathrm{MS}^{3}[802.0(55) \rightarrow \mathbf{1 1 5 7 . 0}(\mathbf{5 5})]$ & $\begin{array}{l}1005.6105\left(\mathbf{y}_{\mathbf{1 1}}{ }^{+}-\mathbf{a a}(\mathbf{1 5}), 53,1.4\right), 892.5259\left(\mathbf{y}_{\mathbf{1 1}}{ }^{+}-\mathbf{a a}(\mathbf{1 4 - 1 5}), 100,0.9\right), 807.4726 \\
\left(\mathbf{y}_{\mathbf{1 1}}{ }^{+}-\mathbf{a a}(\mathbf{1 3 - 1 5}), 59,0.4\right), 679.4142\left(\mathbf{y}_{\mathbf{1 1}}{ }^{+}-\mathbf{a a}(\mathbf{1 2 - 1 5}), 79,0.7\right), 594.3614\left(\mathbf{y}_{\mathbf{1 1}}{ }^{+}-\right. \\
\mathbf{a a}(\mathbf{1 1 - 1 5}), 75,0.7), 509.3084\left(\mathbf{y}_{\mathbf{1 1}}{ }^{+}-\mathbf{a a}(\mathbf{1 0 - 1 5}), 36,0.4\right), 381.2506\left(\mathbf{y}_{\mathbf{1 1}}{ }^{+}-\mathbf{a a}(\mathbf{9 -}\right. \\
\mathbf{1 5}), 14,2.6)\end{array}$ \\
\hline 2 & $(+) \mathrm{MS}^{3}[802.0(55) \rightarrow \mathbf{4 4 7 . 0}(\mathbf{6 5})]$ & $362.1715\left(\mathbf{b}_{3}^{+}, 51,1.4\right), 215.1029\left(\mathbf{b}_{2}^{+}, 8,1.4\right)$ \\
\hline 2 & (-) full MS & $1646.9202\left([\mathbf{M}-\mathbf{H}+\mathbf{H C O O H}]^{-}, 100,2.4\right), 1600.9127$ ([M-H]', 9, 1.2) \\
\hline 2 & $(-) \mathrm{MS}^{2}[\mathbf{1 6 0 1 . 0}(45)]$ & $1570.9005\left(\mathbf{v}_{15}, 100,0.1\right)$ \\
\hline 2 & $(-) \mathrm{MS}^{3}[1601.0(55) \rightarrow \mathbf{1 5 7 1 . 0}(\mathbf{5 5})]$ & $\begin{array}{l}1443.8381\left(\mathbf{v}_{\mathbf{1 4}}^{-}, 1,0.8\right), 1386.8170\left(\mathbf{y}_{\mathbf{1 3}}^{-}, 2,1.1\right), 1239.7493\left(\mathbf{y}_{\mathbf{1 2}}^{-}, 1,1.8\right), \\
1154.6952\left(\mathbf{y}_{\mathbf{1 1}}^{-}, 100,0.8\right), 1057.6432\left(\mathbf{y}_{\mathbf{1 0}}^{-}, 1,1.6\right), 944.5580\left(\mathbf{y}_{\mathbf{9}}^{-}, 2,0.5\right), \\
859.5055\left(\mathbf{y}_{\mathbf{8}}^{-}, 6,0.9\right), 774.4527\left(\mathbf{y}_{\mathbf{7}}^{-}, 10,1.0\right), 646.3942\left(\mathbf{y}_{\mathbf{6}}^{-}, 5,1.2\right)\end{array}$ \\
\hline 2 & $(-) \mathrm{MS}^{3}[1601.0(55) \rightarrow \mathbf{1 1 5 5 . 0}(\mathbf{5 5})]$ & $\begin{array}{l}1057.6416\left(\mathbf{y}_{10}^{-}, 2,0.1\right), 944.5581\left(\mathbf{y}_{\mathbf{9}}^{-}, 22,0.6\right), 859.5053\left(\mathbf{y}_{\mathbf{8}}^{-}, 70,0.7\right), \\
774.4526\left(\mathbf{y}_{7}^{-}, 100,0.9\right), 646.3939\left(\mathbf{y}_{\mathbf{6}}^{-}, 60,0.8\right), 561.3412\left(\mathbf{y}_{\mathbf{5}}^{-}, 42,1.1\right) \\
476.2885\left(\mathbf{y}_{\mathbf{4}}^{-}, 26,1.5\right), 348.2299\left(\mathbf{y}_{\mathbf{3}}^{-}, 6,1.7\right)\end{array}$ \\
\hline
\end{tabular}


Table S3. Positive and negative ion HRESIMS ${ }^{\mathrm{n}}$ data of tylopeptins A (3) and B (4)

\begin{tabular}{|c|c|c|}
\hline cpd & $(+) /(-)$ scan mode $[\mathrm{m} / \mathrm{z}(\mathrm{NCE}$ in $\%)]$ & $\mathrm{m} / \mathrm{z}$ (fragment ion, relative intensity in $\%$, error in $\mathrm{ppm}$ ) \\
\hline 3 & (+) full MS & $1553.9010\left([\mathbf{M}+\mathbf{H}]^{+}, 22,2.6\right), 777.4565\left([\mathbf{M}+2 \mathbf{H}]^{2+}, 100,0.4\right)$ \\
\hline 3 & (+) $\mathrm{MS}^{2}[1554.0(45)]$ & $\begin{array}{l}1436.7861\left(\mathbf{b}_{\mathbf{1 4}}^{+}, 1,2.4\right), 1308.7274\left(\mathbf{b}_{13}^{+}, 62,2.8\right), 1223.6759\left(\mathbf{b}_{12}^{+}, 17,2.0\right), \\
1110.5916\left(\mathbf{b}_{11}^{+}, 49,2.3\right), 1039.5543\left(\mathbf{b}_{10}^{+}, 22,2.7\right), 954.5018\left(\mathbf{b}_{9}^{+}, 11,2.6\right), \\
867.4698\left(\mathbf{b}_{\mathbf{8}}^{+}, 100,2.9\right), 782.4169\left(\mathbf{b}_{7}^{+}, 49,3.5\right), 711.3806\left(\mathbf{b}_{\mathbf{6}}^{+}, 3,2.5\right), \\
583.3222\left(\mathbf{b}_{\mathbf{5}}^{+}, 30,2.9\right), 512.2856\left(\mathbf{b}_{\mathbf{4}}^{+}, 30,2.1\right)\end{array}$ \\
\hline 3 & $(+) \mathrm{MS}^{3}[1554.0(55) \rightarrow \mathbf{8 6 7 . 0}(\mathbf{4 5})]$ & $\begin{array}{l}782.4188\left(\mathbf{b}_{7}^{+}, 90,1.0\right), 583.3235\left(\mathbf{b}_{5}^{+}, 52,2.5\right), 512.2866\left(\mathbf{b}_{4}^{+}, 100,0.2\right), \\
413.2177\left(\mathbf{b}_{3}^{+}, 59,1.5\right), 328.1658\left(\mathbf{b}_{2}^{+}, 14,0.6\right)\end{array}$ \\
\hline 3 & (-) full MS & 1597.8995 ([M-H+HCOOH]', 100, 2.5), 1551.8935 ([M-H]', 8, 2.0) \\
\hline 3 & (-) $\mathrm{MS}^{2}[\mathbf{1 5 5 2 . 0}(\mathbf{5 5})]$ & $1521.8873\left(\mathbf{v}_{15} \cdot 100,4.9\right)$ \\
\hline 3 & $(-) \mathrm{MS}^{3}[1552.0(55) \rightarrow \mathbf{1 5 2 2 . 0}(\mathbf{5 5})]$ & $\begin{array}{l}1293.7946\left(\mathbf{v}_{\mathbf{1 4}}^{-}, 9,3.6\right), 1194.7263\left(\mathbf{v}_{\mathbf{1 3}}^{-}, 10,3.9\right), 1109.6733\left(\mathbf{v}_{\mathbf{1 2}}^{-}, 9,4.1\right), \\
1010.6046\left(\mathbf{v}_{\mathbf{1 1}}^{-}, 32,4.2\right), 939.5685\left(\mathbf{v}_{\mathbf{1 0}}^{-}, 19,5.5\right), 811.5082\left(\mathbf{v}_{\mathbf{9}}^{-}, 56,4.3\right), \\
740.4708\left(\mathbf{v}_{\mathbf{8}^{-}}^{-}, 21,4.3\right), 655.4179\left(\mathbf{v}_{\mathbf{7}}^{-}, 29,4.7\right), 598.3959\left(\mathbf{y}_{\mathbf{6}}^{-}, 20,4.2\right), \\
513.3431\left(\mathbf{y}_{\mathbf{5}}^{-}, 16,4.9\right), 442.3057\left(\mathbf{y}_{\mathbf{4}}^{-}, 6,5.0\right)\end{array}$ \\
\hline 4 & (+) full MS & $1539.8864\left([\mathbf{M + H}]^{+}, 23,1.9\right), 770.4480\left([\mathbf{M}+2 \mathbf{H}]^{2+}, 100,0.4\right)$ \\
\hline 4 & $(+) \mathrm{MS}^{2}[1540.0(45)]$ & $\begin{array}{l}1422.7760\left(\mathbf{b}_{14}{ }^{+},<1,1.4\right), 1294.7119\left(\mathbf{b}_{13}{ }^{+}, 69,2.7\right), 1209.6589\left(\mathbf{b}_{12}{ }^{+}, 19,3.1\right), \\
1096.5757\left(\mathbf{b}_{11}^{+}, 52,2.6\right), 1025.5383\left(\mathbf{b}_{10}{ }^{+}, 26,3.1\right), 940.4862\left(\mathbf{b}_{9}^{+}, 11,2.7\right), \\
853.4542\left(\mathbf{b}_{\mathbf{8}}^{+}, 100,2.9\right), 768.4014\left(\mathbf{b}_{7}^{+}, 59,3.3\right), 697.3635\left(\mathbf{b}_{\mathbf{6}}^{+}, 4,4.7\right), \\
569.3065\left(\mathbf{b}_{5}^{+}, 22,3.0\right), 498.2695\left(\mathbf{b}_{\mathbf{4}}^{+}, 22,3.2\right)\end{array}$ \\
\hline 4 & $(+) \mathrm{MS}^{3}[1540.0(55) \rightarrow \mathbf{8 5 3 . 0}(\mathbf{4 5})]$ & $\begin{array}{l}768.4030\left(\mathbf{b}_{7}^{+}, 100,1.2\right), 697.3651\left(\mathbf{b}_{\mathbf{6}}^{+}, 4,2.4\right) 569.3081\left(\mathbf{b}_{5}^{+}, 37,0.2\right), \\
498.2711\left(\mathbf{b}_{\mathbf{4}}^{+}, 65,0.1\right), 413.2180\left(\mathbf{b}_{3}^{+}, 37,0.7\right), 328.1657\left(\mathbf{b}_{2}^{+}, 10,0.3\right)\end{array}$ \\
\hline 4 & (-) full MS & 1583.8862 ([M-H+HCOOH]', 100, 3.7), 1537.8767 ([M-H]', 9, 1.2) \\
\hline 4 & (-) $\mathrm{MS}^{2}[\mathbf{1 5 3 8 . 0}(55)]$ & $1507.8698\left(\mathbf{v}_{15}, 100,3.7\right)$ \\
\hline 4 & $(-) \mathrm{MS}^{3}[1538.0(55) \rightarrow \mathbf{1 5 0 8 . 0}(\mathbf{4 5})]$ & $\begin{array}{l}1279.7794\left(\mathbf{v}_{\mathbf{1 4}}^{-}, 6,4.0\right), 1180.7110\left(\mathbf{v}_{\mathbf{1 3}}^{-}, 7,4.3\right), 1095.6572\left(\mathbf{v}_{\mathbf{1 2}}^{-}, 8,3.7\right), \\
1010.6052\left(\mathbf{v}_{\mathbf{1 1}}^{-}, 24,4.7\right), 939.5669\left(\mathbf{v}_{\mathbf{1 0}}^{-}, 13,3.8\right), 811.5081\left(\mathbf{v}_{\mathbf{9}}^{-}, 39,4.2\right), \\
740.4706\left(\mathbf{v}_{\mathbf{8}^{-}}^{-}, 13,4.1\right), 655.4177\left(\mathbf{v}_{\mathbf{7}}^{-}, 17,4.4\right), 598.3961\left(\mathbf{y}_{\mathbf{6}}^{-}, 10,4.5\right), \\
513.3430\left(\mathbf{y}_{\mathbf{5}}^{-}, 7,4.7\right)\end{array}$ \\
\hline
\end{tabular}


Table S4. List of specimens and reference sequences used for molecular phylogeny. Type strains are indicated by $(\mathbf{T})$.

\begin{tabular}{|c|c|c|c|c|c|c|}
\hline \multirow[t]{2}{*}{ Species } & \multirow[t]{2}{*}{ Strain no. } & \multirow[t]{2}{*}{ Origin } & \multicolumn{3}{|c|}{ GenBank accession } & \multirow[t]{2}{*}{ References } \\
\hline & & & ITS & EF1- $\alpha$ & RPB2 & \\
\hline $\begin{array}{l}\text { Hypomyces } \\
\text { lactifluorum }\end{array}$ & TAA 171006 & N/A & --- & --- & EU710773 & Jaklitsch et al. $(2008)^{1}$ \\
\hline H. lactifluorum & TAAM 170476 & USA & FN859432 & FN868751 & --- & Põldmaa $(2011)^{2}$ \\
\hline H. rosellus & N/A & N/A & EU340833 & --- & --- & $\begin{array}{l}\text { Sharma and Singh (direct } \\
\text { submission) }\end{array}$ \\
\hline H. rosellus & TFC 95-105 & N/A & --- & HF911695 & EU710774 & $\begin{array}{l}\text { Jaklitsch et al. }(2008)^{1} \text {; } \\
\text { Tamm and Põldmaa } \\
(2013)^{3}\end{array}$ \\
\hline H. subiculosus & $\begin{array}{l}\text { DAOM } \\
226568\end{array}$ & N/A & EU280093 & --- & --- & $\begin{array}{l}\text { Hoyos-Carvajal et al. } \\
(2009)^{4}\end{array}$ \\
\hline H. subiculosus & TFC 97-166 & Puerto Rico & --- & FN868770 & EU710776 & $\begin{array}{l}\text { Jaklitsch et al. }(2008)^{1} \text {; } \\
\text { Põldmaa }(2011)^{2}\end{array}$ \\
\hline $\begin{array}{l}\text { Sepedonium } \\
\text { ampullosporum }\end{array}$ & CBS 392.52 & $\begin{array}{l}\text { Netherlands } \\
(\mathbf{T})\end{array}$ & AF054854 & --- & --- & Sahr et al. $(1999)^{5}$ \\
\hline S. ampullosporum & $\mathrm{S} 15$ & Germany & AF054853 & --- & --- & Sahr et al. $(1999)^{5}$ \\
\hline S. brunneum & S171 & USA & KT946841 & KU041491 & KU041503 & This study* \\
\hline S. brunneum & S172 & USA & KT946842 & KU041492 & KU041504 & This study* \\
\hline S. chalcipori & S33 & Germany & KT946845 & KU041495 & KU041507 & This study* \\
\hline S. chalcipori & $\mathrm{S} 35$ & Germany & KT946840 & KU041490 & KU041502 & This study* \\
\hline S. chalcipori & $\mathrm{S} 44$ & New Zealand & KT946846 & KU041496 & KU041508 & This study* \\
\hline S. chalcipori & S46 & New Zealand & KT946847 & KU041497 & KU041509 & This study* \\
\hline S. aff. chalcipori & KSH 883 & Chile & KT946848 & KU041498 & KU041510 & This study \\
\hline S. chlorinum & S247 & USA & KT946843 & KU041493 & KU041505 & This study \\
\hline S. chlorinum & $\mathrm{S} 248$ & USA & KT946844 & KU041494 & KU041506 & This study \\
\hline S. chlorinum & $\mathrm{S} 38$ & Germany & AF054866 & --- & --- & Sahr et al. $(1999)^{5}$ \\
\hline S. chrysospermum & S160 & Germany & AF054845 & --- & --- & Sahr et al. $(1999)^{5}$ \\
\hline S. chrysospermum & S47 & Germany & AF054844 & --- & --- & Sahr et al. $(1999)^{5}$ \\
\hline S. laevigatum & CBS 101645 & $\operatorname{USA}(\mathbf{T})$ & AF054858 & --- & --- & Sahr et al. $(1999)^{5}$ \\
\hline S. laevigatum & S88 & Germany & AF054857 & --- & --- & Sahr et al. $(1999)^{5}$ \\
\hline S. microspermum & S177 & USA & AF054852 & --- & --- & Sahr et al. (1999) ${ }^{5}$ \\
\hline S. microspermum & $\mathrm{S} 23$ & Germany & AF054851 & --- & --- & Sahr et al. $(1999)^{5}$ \\
\hline S. microspermum & $\mathrm{S} 24$ & Germany & AF054847 & --- & --- & Sahr et al. $(1999)^{5}$ \\
\hline S. tulasneanum & S165 & Germany & AF054860 & --- & --- & Sahr et al. $(1999)^{5}$ \\
\hline S. tulasneanum & $\mathrm{S} 29$ & Germany & AF054859 & --- & --- & Sahr et al. $(1999)^{5}$ \\
\hline $\begin{array}{l}\text { Trichoderma } \\
\text { aerugineum }\end{array}$ & CBS 120541 & Germany (T) & FJ860720 & FJ860608 & FJ860516 & $\begin{array}{l}\text { Jaklitsch and Voglmayr } \\
(2015)^{6}\end{array}$ \\
\hline
\end{tabular}

N/A = no information available; * strains were sequenced before by Sahr et al. $(1999)^{5}$, but not considered in this study

\section{References:}

(1) Jaklitsch, W. M.; Põldmaa, K.; Samuels, G. J. Mycologia 2008, 100, 962-984.

(2) Põldmaa, K. Stud. Mycol. 2011, 68, 1-34.

(3) Tamm, H.; Põldmaa, K. Fungal Biol. 2013, 117, 348-367.

(4) Hoyos-Carvajal, L.; Orduz, S.; Bissett, J. Fungal Genet. Biol. 2009, 46, 615-631.

(5) Sahr, T.; Ammer, H.; Besl, H.; Fischer, M. Mycologia 1999, 91, 935-943.

(6) Jaklitsch, W. M.; Voglmayr, H. Stud. Mycol. 2015, 80, 1-87. 
Table S5. Characteristics of calculated MAFFT alignments and Gblocks settings

\begin{tabular}{|c|c|c|c|}
\hline Alignment & ITS & EF1- $\alpha$ & RPB2 \\
\hline Number of sequences & 26 & 13 & 13 \\
\hline \multicolumn{4}{|l|}{ Number of positions: } \\
\hline Initial MAFFT alignment & 719 & 1431 & 1117 \\
\hline Cured MAFFT alignment (Gblocks) & 574 & 876 & 1036 \\
\hline Fraction & $80 \%$ & $61 \%$ & $93 \%$ \\
\hline \multicolumn{4}{|l|}{ Pairwise identity: } \\
\hline Initial MAFFT alignment & $88.9 \%$ & $93.2 \%$ & $86.6 \%$ \\
\hline Cured MAFFT alignment (Gblocks) & $89.5 \%$ & $93.2 \%$ & $86.9 \%$ \\
\hline \multicolumn{4}{|l|}{ Minimum number of sequences for: } \\
\hline a conserved position & 13 & 7 & 7 \\
\hline a flanking position & 21 & 11 & 11 \\
\hline $\begin{array}{l}\text { Maximum number of contiguous non- } \\
\text { conserved positions }\end{array}$ & 8 & 8 & 8 \\
\hline Minimum length of a block & 5 & 5 & 5 \\
\hline Allowed gap positions & With half & With half & With half \\
\hline Number of selected blocks & 17 & 1 & 1 \\
\hline Flanking positions of selected blocks & 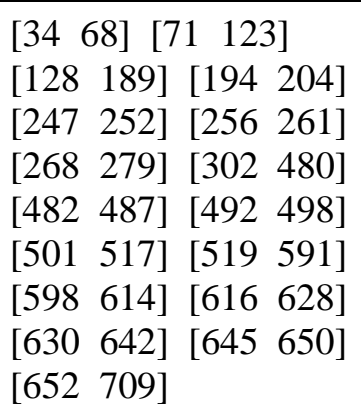 & [524 1399] & {$\left[\begin{array}{ll}42 & 1077\end{array}\right]$} \\
\hline
\end{tabular}


Table S6. Calculated RAxML values of ITS and MGA alignment

\begin{tabular}{lll}
\hline Alignment & ITS & MGA \\
\hline $\ln (\mathrm{L})$ & -2219.1484 & -8709.4025 \\
\hline$\alpha$-value & 0.2502 & 0.1778 \\
\hline Tree length & 0.6777 & 0.6888 \\
\hline Substitution rates: & & \\
$\mathrm{A} \leftrightarrow \mathrm{C}$ & 2.026387 & 1.246994 \\
$\mathrm{~A} \leftrightarrow \mathrm{G}$ & 1.664540 & 2.727267 \\
$\mathrm{~A} \leftrightarrow \mathrm{T}$ & 2.027866 & 1.066706 \\
$\mathrm{C} \leftrightarrow \mathrm{G}$ & 1.293141 & 0.921858 \\
$\mathrm{C} \leftrightarrow \mathrm{T}$ & 4.250045 & 6.842360 \\
$\mathrm{G} \leftrightarrow \mathrm{T}$ & 1.000000 & 1.000000 \\
\hline Base frequencies: & & \\
$f \pi_{(\mathrm{A})}$ & 0.2259 & 0.2349 \\
$f \pi_{(\mathrm{C})}$ & 0.3124 & 0.2955 \\
$f \pi_{(\mathrm{G})}$ & 0.2616 & 0.2584 \\
$f \pi_{(\mathrm{T})}$ & 0.2001 & 0.2112 \\
\hline
\end{tabular}

